\title{
Synoptic Features Responsible for Heat Waves in Central Africa, a Region with Strong Multidecadal Trends
}

\author{
LISUO HU \\ State Key Laboratory of Satellite Ocean Environment Dynamics, Second Institute of Oceanography, Ministry of \\ Natural Resources, Hangzhou, and State Key Laboratory of Numerical Modeling for Atmospheric \\ Sciences and Geophysical Fluid Dynamics, Institute of Atmospheric Physics, Chinese Academy \\ of Sciences, and University of Chinese Academy of Sciences, Beijing, China \\ JING-JIA LUO \\ Institute for Climate and Application Research/Key Laboratory of Meteorological Disaster of \\ Ministry of Education (KLME), Nanjing University of Information Science and Technology, Nanjing, China

\section{GANG HUANG} \\ State Key Laboratory of Numerical Modeling for Atmospheric Sciences and Geophysical Fluid Dynamics, Institute \\ of Atmospheric Physics, Chinese Academy of Sciences, and University of Chinese Academy of Sciences, \\ Beijing, and Laboratory for Regional Oceanography and Numerical Modeling, Qingdao National \\ Laboratory for Marine Science and Technology, Qingdao, China \\ MATTHEW C. WHEELER \\ Bureau of Meteorology, Melbourne, Victoria, Australia
}

(Manuscript received 26 November 2018, in final form 8 August 2019)

\begin{abstract}
Central Africa (CA) is identified as a location of a large positive trend of the occurrence of heat waves (HWs) during 1979-2016, appearing to result mostly from a regime shift around the year 2000. Therefore, we study the evolution of synoptic features associated with the occurrence of HW events in CA. It is found that the HW-related circulation is typically characterized by an anomalous convergence in the upper troposphere but there are important differences for HW events occurring in the south region of CA (CA_S) versus the north region (CA_N). For the occurrence of the HW events in CA_S, the anomalous subsidence associated with upper troposphere anomalous convergence is the dominant factor for their occurrence and magnitude: the strong subsidence leads to warming through greater solar insolation. The HW events in CA_S are also accompanied by an anomalous surface anticyclone in the north with anomalous northerly flow transporting heat into the CA_S region. In contrast, although the HW events in CA_N are also associated with upper troposphere anomalous convergence, the intensity of the convergence is weak with small solar insolation. Instead, the anomalous warm advection is the main factor for determining the magnitude of the HW events in CA_N, induced by the prevailing northerly winds acting on the anomalous temperature gradient. Thus, the synoptic features associated with HW events in the CA_N and CA_S are quite different despite their nearby locations. The discovered dominant factors for the HW events in CA can be used to improve the forecast skill.
\end{abstract}

\section{Introduction}

As a result of anthropogenic global warming, extreme heat $(\mathrm{EH})$ is projected to become more intense, more frequent, and longer lasting in the coming decades and

Corresponding authors: Jing-Jia Luo, jingjia_luo@hotmail.com; Gang Huang,hg@mail.iap.ac.cn has attracted great attention by society and in the scientific literature (e.g., Meehl and Tebaldi 2004; Kunkel et al. 2010; Alexander et al. 2013; Lau and Nath 2012; Weaver et al. 2014). EH exerts notable influences on both socioeconomic and public health, increasing the consumption of electricity and water, causing forest fires, crop losses, and heat-related illness, such as heat stroke, heat exhaustion, and various respiratory and 
cardiovascular diseases (Zhang and Wang 2002; Meehl and Tebaldi 2004; Luber and McGeehin 2008; Coumou and Rahmstorf 2012; IPCC 2012; Lu and Chen 2016). For example, western Russia suffered a recordbreaking heat wave in 2010, causing 55000 heat-related deaths, 500 wildfires, and a $30 \%$ reduction in its grain harvest (Dole et al. 2011; Grumm 2011; Coumou and Rahmstorf 2012). In fact, EH is reported to be the most dominant cause of weather-related human mortality among heat, cold, drought, storm, and flood events (Alexander et al. 2013). Therefore, the increasing threat of EH calls for a detailed understanding of the physical causes of its occurrence.

$\mathrm{EH}$ is often accompanied by notable changes in the ambient atmospheric circulation and precipitation fields, as well as in the condition of the nearby land and ocean surface (Hu et al. 2011, 2012; Lau and Nath 2012, 2014; Luo and Lau 2017). Since large-scale circulation is generally considered as a major factor affecting temperature, previous studies have suggested that anticyclonic anomalies induce the occurrence of $\mathrm{EH}$ in various regions (Meehl and Tebaldi 2004; Maheras et al. 2006; Gershunov et al. 2009; Chen and Lu 2015; Lu and Chen 2016; Luo and Lau 2017). Air temperature is increased through both adiabatic heating and increasing solar radiation at the surface induced by subsidence, which is associated with anomalous anticyclones (Zaitchik et al. 2006; Loikith and Broccoli 2012; Chen and Lu 2015).

Not only the vertical flow but also the horizontal flow affects air temperature through temperature advection. During July-August over the eastern Mediterranean region, Ziv et al. (2004) found that the temperature anomaly is attributable to the combined effect of horizontal advection by prevailing northwesterly winds and the warming associated with subsidence. Moreover, Harpaz et al. (2014) concluded that the occurrences of EH in the eastern Mediterranean region are controlled by the intensity of the temperature advection, but not by the prevailing subsidence: the weakening of the northeasterly winds prior to hot events is the dominant factor.

However, the features of the atmospheric general circulation associated with the occurrence of $\mathrm{EH}$ in different regions exhibit significant spatial differences. The circulation affecting neighboring cities (such as Madrid, Spain and Lisbon, Portugal) can be quite different (García-Herrera et al. 2005). For instance, southerly anomalies transporting heat from the south are the dominant factor for the occurrence of EH in Madrid, while anomalous easterly airflows that have been previously heated are important to the $\mathrm{EH}$ in Lisbon. In the North America, Loikith and Broccoli (2012) investigated the characteristics of observed atmospheric circulation patterns associated with temperature extremes and found that patterns vary based on latitude, season, and distance to important geographic features (e.g., mountains and coastlines) and pointed out that the anomalous circulation responsible for $\mathrm{EH}$ over the southern domain is distinct from the typical anticyclonic anomaly for other regions. EH in China also has a similar discrepancy. Chen and Lu (2015) compared the composite synoptic circulation anomalies associated with extreme heat in eastern China and classified them into three categories: typical extratropical pattern, monsoonal pattern, and foehn pattern (strong winds blowing from the mountains to the plains result in the foehn effect, which involves drier and warmer air) ( $\mathrm{Lu}$ and Chen 2016). This indicates that the impacts of monsoon and topography should be taken into consideration. Hence, it is necessary to consider the diversity and regional features when studying the circulation associated with the occurrence of $\mathrm{EH}$ in each location.

Engelbrecht et al. (2015) found that temperatures over parts of the subtropics and central tropical Africa have been rising at more than twice the global rate. Both the relatively strong signals of projected climate change in Africa and the relatively low economic development of Africa increase its vulnerability to the adverse impacts of climate change (Engelbrecht et al. 2015; Nangombe et al. 2018). Africa is one of the most vulnerable continents due to its high exposure and low adaptive capacity (IPCC 2014). In particular, there are tens of millions of subsistence farmers in Africa who depend on agriculture. In the past three decades, Africa suffered $27 \%$ of the world's reported fatalities from natural catastrophes (614250 people) and experienced 1560 weather-related catastrophes, such as drought, heat waves, storms, and floods (Munich Re 2011; Russo et al. 2016).

Previous studies mainly focus on the synoptic circulation associated with EH in extratropical regions (Loikith and Broccoli 2012; Chen and Lu 2015; Luo and Lau 2017). However, there are few studies that focus on the heat wave (HW)-related circulation in tropical regions. For example, Fontaine et al. (2013) analyzed the recent changes in heat wave occurrences and atmospheric circulation in Northern Africa during spring and summer, but did not investigate the synoptic features that are responsible for heat waves events. In the present study, we analyze synoptic features and circulation patterns accompanying the occurrence of heat wave events in central Africa (CA), a location of strong multidecadal trends of EH. This study is expected to improve the understanding 
of EH in CA that may help improve the forecast of the occurrence of $\mathrm{EH}$ in this region.

The remainder of this paper is organized as follows. Section 2 introduces the datasets used in this research and definitions of EH. In section 3, CA is chosen because of its strong multidecadal trends and further it is divided into two subregions for detailed analysis. Section 4 provides a discussion of the evolution of synoptic and circulation patterns associated with HW events. Section 5 examines the dominant factor affecting the magnitude of HW events. The main conclusions and discussion are presented in section 6 .

\section{Data and definitions}

\section{a. Data}

For the analysis focusing on the satellite era (19792016), daily maximum temperature $T_{\max }$ datasets are provided by one observationally based gridded product and retrieved from two atmospheric reanalyses. These datasets are listed below.

1) The Berkeley Earth Surface Temperature (BEST; Rohde et al. 2013a,b), which provides data on a $1^{\circ} \times 1^{\circ}$ grid from 1880 until recent years.

2) The European Centre for Medium-Range Weather Forecasts (ECMWF) interim reanalysis (ERAInterim; Dee et al. 2011), which provides data on a horizontal resolution of $0.75^{\circ}$ latitude $\times 0.75^{\circ}$ longitude and 23 pressure levels from 1000 to $200 \mathrm{hPa}$.

3) The National Centers for Environmental Prediction (NCEP)-U.S. Department of Energy (DOE) AMIP-II reanalysis (NCEP2; Kanamitsu et al. 2002) during $1979-2016$ on a $1.904^{\circ} \times 1.875^{\circ}$ grid.

We primarily make use of the daily $T_{\max }$ anomalies in this study, which are computed by subtracting the climatological seasonal cycle (1979-2016). The latter is obtained by computing the 38-yr averages for individual calendar days and then performing a 31-day running mean. Anomalies rather than actual temperatures are used to avoid temporal biases associated with seasonal variations in climatological mean temperature; such biases could be acute during the transition seasons (e.g., Loikith and Broccoli 2012).

To analyze the pertinent synoptic features responsible for HW events, we have to use reanalysis data. Barbier et al. (2018) indicated that ERA-Interim is better than NCEP2 in characterizing heat waves in Sahel, with fewer departures from BEST for ERA-Interim. Hence, ERA-Interim reanalysis data are used to define extreme heat first, and then compared with BEST gridded data and NCEP2 reanalysis data due to the fact that data are sparse in Africa. The observed results presented in this study are obtained from daily grids retrieved from reanalysis data of mean $2-\mathrm{m}$ temperature $\left(T_{\text {mean }}\right)$, surface temperature $\left(T_{s}\right)$, precipitation $(\operatorname{Pr})$, surface pressure $\left(P_{s}\right)$, surface wind at $10 \mathrm{~m}$, wind from 1000 to $200 \mathrm{hPa}, 500-\mathrm{hPa}$ vertical velocity (omega), 850-hPa specific humidity $(q)$, surface solar radiation (ssrd), and downward surface sensible heat flux (hfss). To calculate the daily anomalies of these variables, we utilized the same method for the temperature anomalies.

\section{b. Definitions}

Prolonged exposure to extremely high temperatures can lead to heat-related illnesses and result in an increase in mortality, especially in the elderly (Kilbourne 1997; Sandor and Howe 1997; Luber and McGeehin 2008; Lippmann et al. 2013). Mortality risk begins to rise as the temperatures increases from populationspecific threshold values, producing a J- or V-shaped relation. There are important differences in vulnerability between populations, depending on climate, culture, infrastructure (housing), and other factors (Curriero et al. 2002; Baccini et al. 2008; Kovats and Hajat 2008). Kovats and Hajat (2008) indicated that most homes have an indoor temperature of $63^{\circ}-87^{\circ} \mathrm{F}$ $\left(17.2^{\circ}-30.6^{\circ} \mathrm{C}\right)$, and people do not comfortably live in temperatures outside this range. Even the tolerance range of an individual is usually much less than this, and the range becomes narrower with age or illness (Kovats and Hajat 2008).

Kim et al. (2017) investigated the trend of outbreak of thermal illness patients based on temperature during 2002-13 in South Korea. They found that the number of patients with heat-related illnesses increased as the daily maximum temperature increased $1^{\circ} \mathrm{C}$ above $29.5^{\circ} \mathrm{C}$. In addition, other studies showed that temperatures above $80^{\circ} \mathrm{F}\left(26.7^{\circ} \mathrm{C}\right.$; Deschênes and Moretti 2009) and $90^{\circ} \mathrm{F}$ (32.2 ${ }^{\circ} \mathrm{C}$; Barreca 2012; Barreca et al. 2016) lead to the increasing of mortality. The specific temperature thresholds associated with human health are around $30^{\circ} \mathrm{C}$ although differences exist among the previous studies.

The 90th percentile of the $T_{\max }$ anomaly distribution (TX90) on a given day $d$ is defined by all 31-day intervals from 1979 to 2016 centered on the calendar day. Therefore, the impact of the jump between the monthly climatology has been avoided. To analyze EH associated with human health, hot days (HDs) are defined as those days when daily $T_{\max }$ anomaly is above the TX90 and daily $T_{\max }$ exceeds $30^{\circ} \mathrm{C}$. When HDs last for three consecutive days or more, HW events are identified. We examine the HW events with two measures, the yearly 


\section{climatology and trend of HDs \& HWs during 1979-2016}
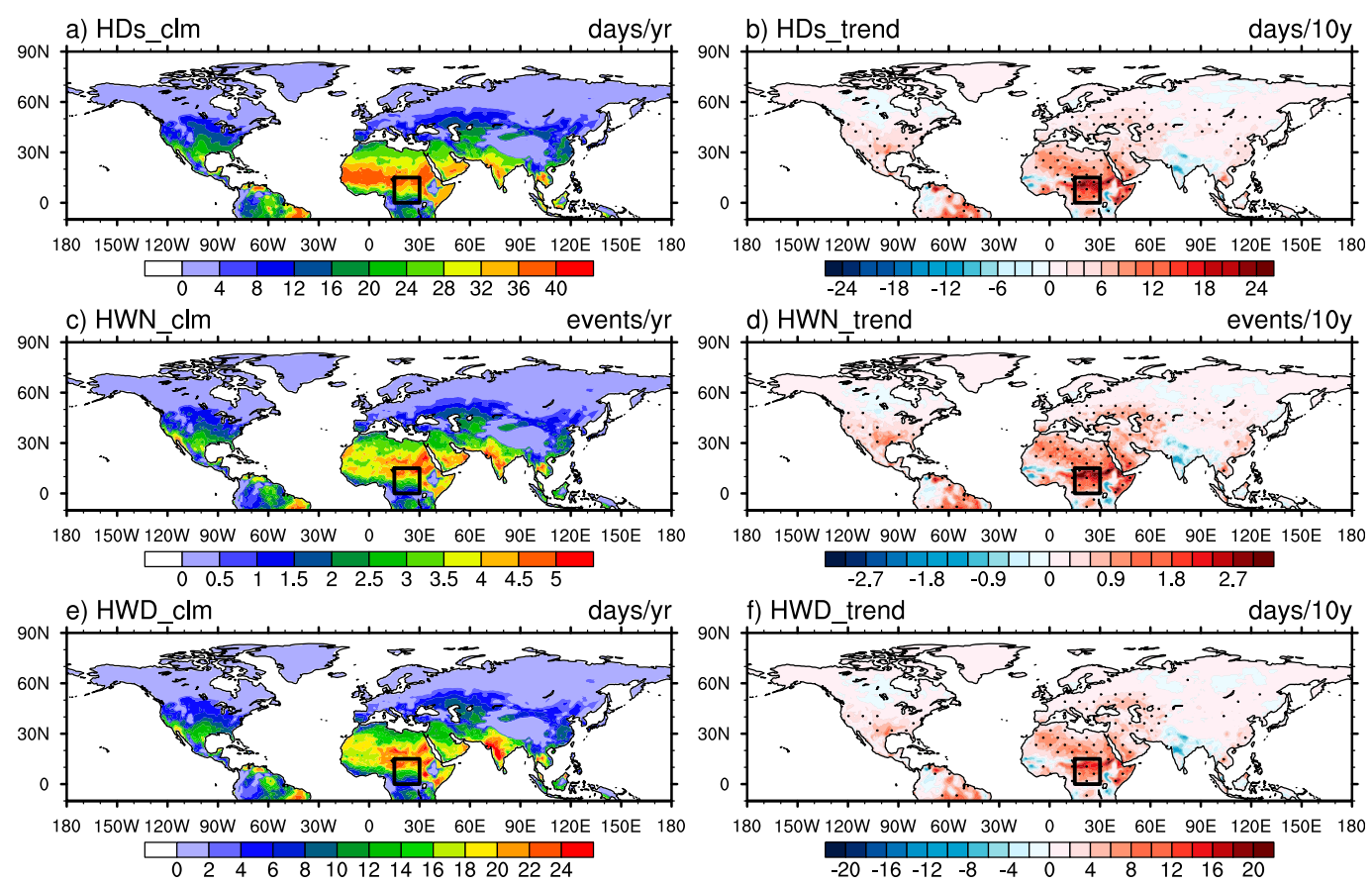

FIG. 1. Climatology and linear trend of (a),(b) HDs, (c),(d) HWN, and (e),(f) HWD during 1979-2016 derived from the ERA-Interim reanalysis data in the North Hemisphere. Dots denote significance at the $95 \%$ confidence level according to the Student's $t$ test. Black boxes denote the CA region.

number of HW events (HWN) and yearly sum of HW days (HWD).

\section{Region selection and subregion classification}

The climatology and trends of HDs, HWN, and HWD during 1979-2016 derived from the ERA-Interim reanalysis data are depicted in Fig. 1. Spatial distributions of the climatology of these variables display a zonally elongated structure with the maximum located around $10^{\circ}-30^{\circ} \mathrm{N}$. EH frequently occurs over central and North Africa and the Arabian and Indian peninsulas. Both the HDs and HW indices (HWN and HWD) show an increasing trend in the most parts of the Northern Hemisphere except the Indian peninsula, where an insignificant decreasing trend is identified. The results clearly show that central Africa $\left(\mathrm{CA} ; 0^{\circ}-15^{\circ} \mathrm{N}, 15^{\circ}-30^{\circ} \mathrm{E}\right)$ is a location with strong multidecadal trends of EH. During 1979-2016, the HDs have increased significantly by approximate 20 days decade ${ }^{-1}$, HWN by 2.5 events decade ${ }^{-1}$, and HWD by 15 days decade ${ }^{-1}$. Because of the increasing threat of $\mathrm{EH}$ in the $\mathrm{CA}$, it is important to improve our understanding of the physical mechanisms for $\mathrm{EH}$ that underpin the forecast of EH.
Regime shift is defined as a rapid shift of climate status from one that is relatively stable to another. It is detected by a method developed by Rodionov (Rodionov 2004,2006 ) based on a sequential $t$ test (details of regime shift detection are provided by NOAA, available at https:// www.beringclimate.noaa.gov/regimes/\#userconsent\#). As shown in Fig. 2, both the HDs and HW indices exhibit prominent upward trends during 1979-2016 but with apparent regime shifts around 2000. There are 14.79 hot days, 1.54 heat wave events, and 6.85 heat wave days per year on average during 1979-2000, and 45.96 hot days, 5.25 heat wave events, and 25.56 heat wave days on average during 2001-16. Due to the low spatial and temporal coverage of observational data prior to 1979 and the availability of satellite data for assimilation in reanalysis since 1979, our analysis is focused on the period of 1979-2016 only. We note that the regime shift around the year 2000 might be induced by multidecadal variability or global warming or the combination of the both. This warrants future studies possibly with longer historical records. We found that the multidecadal linear trends during the two periods before and after 2000 are actually small (Fig. 2). This indicates that the multidecadal trends of EH in CA during 1979-2016 largely result from the regime shift, not from a linearly steady increase. To eliminate the effects of the regime shift on identifying EH and compositing synoptic features 
Changes of HDs \& HWN \& HWD during 1979-2016
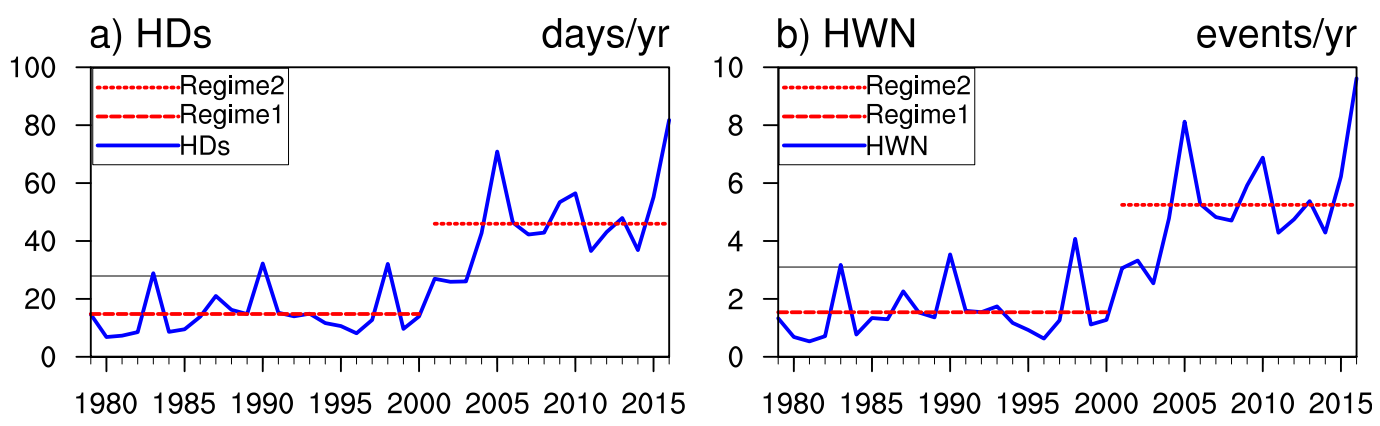

c) HWD

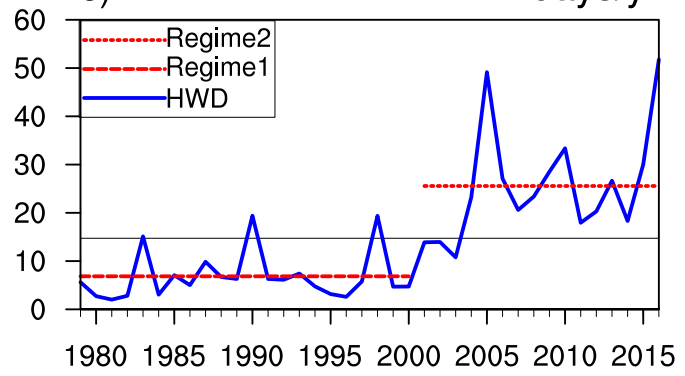

FIG. 2. Time series of the annual number of regionally averaged (a) HDs, (b) HWN, and (c) HWD in CA derived from the ERA-Interim reanalysis data during 1979-2016. Also shown are the detected regimes with each regime shift significant at the $5 \%$ level.

during HW events, the daily anomaly is calculated by removing the 31-day running mean of climatological seasonal cycle based on two periods, 1979-2000 (period 1) and 2001-16 (period 2), from actual values, respectively.

In addition, ERA-Interim, NCEP2, and BEST were compared to evaluate the uncertainties of ERA-Interim reanalysis data. Spatial distributions of climatology of extreme heat are similar between ERA-Interim (Figs. 1a,c,e) and BEST (see Figs. A1a,c,e in the appendix) with pattern correlation coefficients valued $0.902,0.905$, and 0.902 , respectively, but the results derived from ERA-Interim underestimate the mean state of extreme temperature to some extent. Although some differences of linear trends are found, CA is a location with strong multidecadal trends of $\mathrm{EH}$ both in ERA-Interim and BEST. As shown in Fig. A2, both the HDs and HW indices based on the BEST exhibit positive trends with an interdecadal shift around 2000, which is consistent with the results based on the ERA-Interim generally. And the correlation coefficients of the time series of regionally averaged HDs, HWN, and HWD in CA between the BEST and the ERA-Interim data are $0.79,0.74$, and 0.74 , respectively. In contrast the correlations between the BEST and the NCEP2 data are 0.26 , 0.24 , and 0.30. Therefore, compared to the NCEP2, ERA-Interim is better in capturing the $\mathrm{EH}$ in CA with fewer discrepancies from the BEST. Hence we use the
$T_{\max }$ and pertinent variables derived from ERAInterim.

To examine the spatial structure of the daily $T_{\max }$ field in the CA, an empirical orthogonal functions (EOF) analysis is conducted of the daily $T_{\max }$ anomalies over this region during 1979-2016. The first and second EOF mode explains $51.3 \%$ and $22.3 \%$ of the total variance, respectively. It is seen from Figs. $3 \mathrm{a}$ and $3 \mathrm{~b}$ that the EOF modes exhibit a dipole pattern between the south and north region of CA (the boundary is around $7^{\circ} \mathrm{N}$ ). This indicates that CA could be divided into two subregions considering its spatial discrepancy of variations: southern region of CA (CA_S; $\left.0^{\circ}-7^{\circ} \mathrm{N}, 15^{\circ}-30^{\circ} \mathrm{E}\right)$ and the northern region of CA $\left(\mathrm{CA} \_\mathrm{N} ; 7^{\circ}-15^{\circ} \mathrm{N}, 15^{\circ}-30^{\circ} \mathrm{E}\right)$.

In addition, correlation coefficients are computed between the individual daily $T_{\max }$ anomalies in each grid and the spatial mean of CA_S (Fig. 3c) and CA_N (Fig. 3d) for verifying the rationality of the classification. As shown in Fig. 3c, high correlation coefficients mainly occur between $0^{\circ}$ and $7^{\circ} \mathrm{N}$, suggesting that the $T_{\max }$ anomaly in each grid in CA_S covaries with the spatial mean of CA_S. Meanwhile, high correlation coefficients mainly reside between $7^{\circ}$ and $15^{\circ} \mathrm{N}$ in Fig. $3 \mathrm{~d}$, and this indicates that $T_{\max }$ anomaly in each grid in CA_N covaries with the spatial mean of CA_N. In addition, both the seasonal cycle of temperature and precipitation are different in CA_S and CA_N. The southward and 


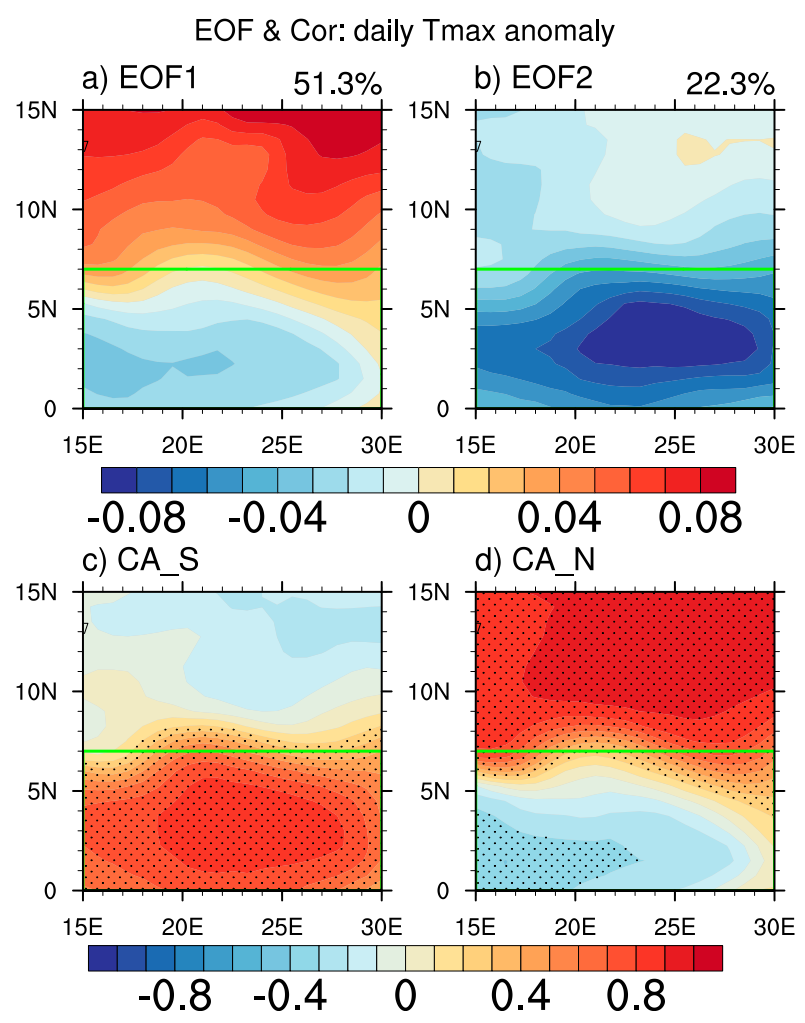

FIG. 3. The (a) first and (b) second EOF mode of daily $T_{\max }$ anomalies, and correlation coefficients of daily $T_{\max }$ anomaly between the individual grids and spatial mean of (c) CA_S and (d) CA_N. Dots denote significance at the $95 \%$ confidence level according to the Student's $t$ test, and green lines indicate $7^{\circ} \mathrm{N}$ latitude.

northward movement of the zonal precipitation band contribute to difference climate feature in CA_S and CA_N. Hence, it is necessary and rational to divide CA into two subregions for better exploring the synoptic features responsible for the HW events in the two regions.

After the subregion classification, regional HW events are identified by the spatial average of daily $T_{\max }$ anomalies and $T_{\max }$ in the CA_S and CA_N, respectively. The 90th percentile values of the spatial mean $T_{\max }$ anomaly distribution are calculated using the same method for individual grid TX90. A regional $\mathrm{HW}$ event is identified in the region when the spatial mean of $T_{\max }$ anomaly is higher than TX90 and spatial $T_{\text {max }}$ exceeds $30^{\circ} \mathrm{C}$ for three consecutive days or more. For example, the daily spatial mean of $T_{\max }, T_{\max }$ anomaly, and TX90 time series in 2016 depicts that 6 HW events and 13 HW events occurred in CA_S and CA_N, respectively (Fig. 4). As shown in Fig. 4, CA_S experiences $\mathrm{HW}$ events mostly during winter, whereas HWs in CA_N occur during autumn and spring. This indicates that HW events in the two subregions do not take place simultaneously.
Heat waves in CA_S mostly occur in winter and spring, with 40 events in winter and 26 events in spring (out of the total 69 events). In CA_S, since the daily maximum temperature are below $30^{\circ} \mathrm{C}$ during the rainy seasons, heat waves mostly occur during dry seasons (winter and early spring). The heat waves in CA_N occur throughout the year, with 54 events in spring, 49 events in summer, 51 events in autumn, and 50 events in winter. There are $21 \mathrm{HW}$ events ( $94 \mathrm{HW}$ days) that took place simultaneously in CA_S and CA_N, indicating that $30.4 \%(10.3 \%)$ of $\mathrm{HW}$ events and $27.4 \%(9.7 \%)$ of HW days in CA_S (CA_N) are concomitant with CA_N (CA_S). Therefore, the level of concomitance between the heat wave occurrences over CA_S and CA_N is low, which is consistent with the results from the EOF analysis of deseasonalized time series of $T_{\max }$.

\section{Evolution of synoptic features during HWs}

Based on the spatial average of $T_{\max }$ and $T_{\max }$ anomaly, 69 and $204 \mathrm{HW}$ events are found in CA_S and CA_N, respectively. In CA_S, there are 40 and 29 HW events during 1979-2000 and 2001-16 with the average length of HWs being 4.8 and 5.2 days, respectively. In CA_N, there are 115 and 89 HW events during 19792000 and 2001-16 with the average length of HWs being 5.0 and 4.4 days, respectively.

In this section, to depict the typical synoptic patterns associated with the occurrence of HW events, we use the identified HW events to construct composite patterns. The synoptic features are examined with the composite anomalies of the pertinent variables responsible for the HW events. The evolution of the average composite patterns are shown from 5 days before the occurrence to 5 days after the end of HW events. To find out if there is contamination between the events that occur close to each other, we composite the cases only when the days before the beginning and after the end of HW events are not superimposed with the period of another HW events. With this criterion, the numbers of cases used in composite analysis for the evolution of HW events are shown in Table 1.

\section{a. $C A \_S$}

Since the composite evolution features of the $T_{\max }$, $T_{\max }$ anomaly, and pertinent variables during two decadal epochs before and after 2000 are similar (Fig. 5) after removing the regime shift, the cases of HW events in the two periods are composited together. The discussion of two periods separately in Fig. 5 is to verify the existence of the regime shift which impact needs to be removed. Due to the significant increase of $T_{\max }$ from period $1(\mathrm{p} 1 ; 1979-2000)$ to period $2(\mathrm{p} 2 ; 2000-16)$, a 

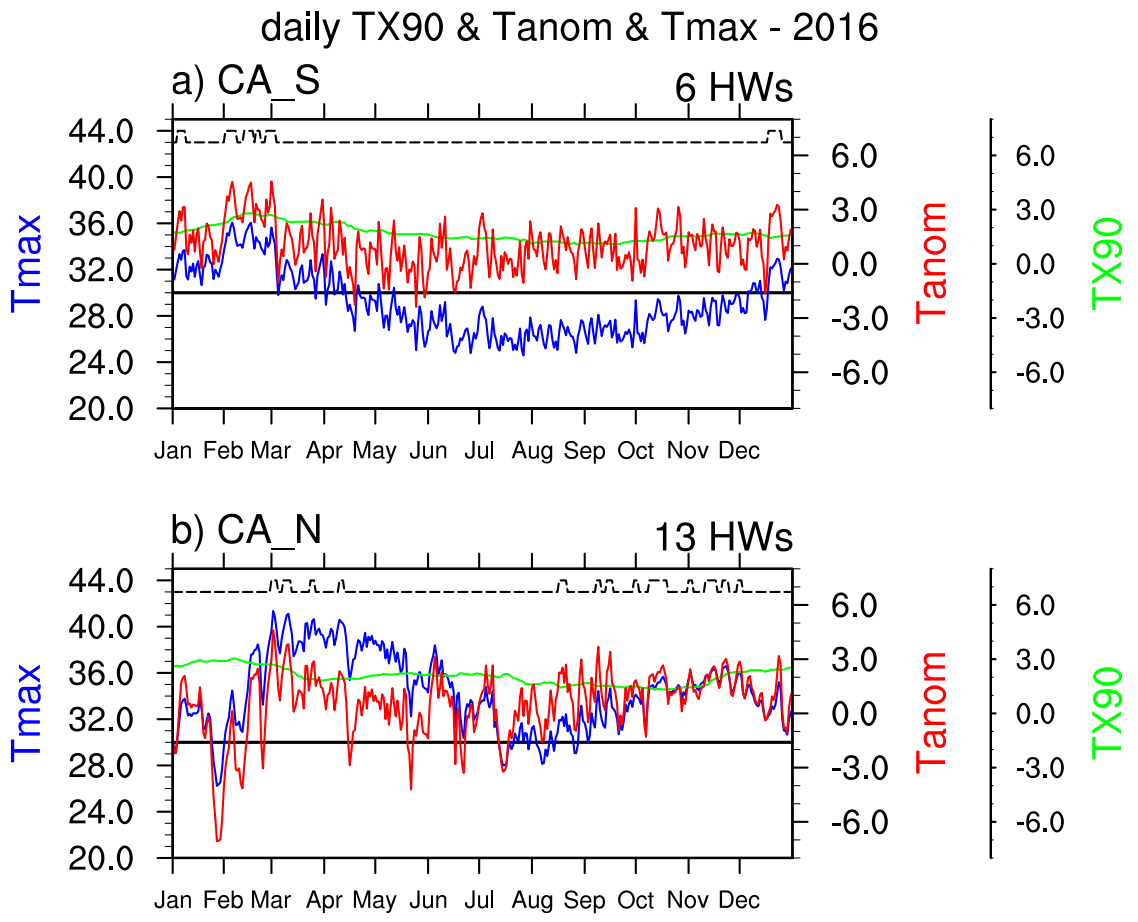

FIG. 4. The daily spatial average of $T_{\max }$ (blue line), $T_{\max }$ anomaly (red line), and TX90 (green line) time series in 2016 over the (a) CA_S and (b) CA_N regions. The black dashed line indicates the occurrence of regional HW events, as each peak represents an HW event.

majority of HW events occur during $\mathrm{p} 2$ if the anomalous $T_{\max }$ and pertinent variables are calculated without removing the impact of the regime shift.

As shown in Fig. 5c, a positive anomaly of $T_{\max }$ occurs during the whole period from ds -5 to de +5 (see Table 1 for definitions of ds and de). The anomaly is $1.12^{\circ} \mathrm{C}$ at ds -5 and basically persists until ds -2 , and then the anomaly rapidly increases to $2.69^{\circ} \mathrm{C}$ at ds -0 . After the end of $\mathrm{HW}$ events, the anomaly decreases dramatically to $1.45^{\circ} \mathrm{C}$ at de +1 and then slowly decreases to $0.86^{\circ} \mathrm{C}$ at de +5 . The $T_{\max }$ anomaly decays more rapidly after the $\mathrm{HW}$ events than the increases before the HW events. The dramatic increase and decrease of temperatures during the HW events suggest that the occurrences of HW events are mostly induced by synoptic disturbances (Chen and $\mathrm{Lu}$ 2015). Due to the large spread among the HW events, especially before ds -2 and after de +1 , strong case-to-case differences exist. Hence, composite analysis based on a large number of cases is necessary to obtain statistically robust results; this is another reason why we composite the cases of HW events during the two periods together.

Associated with the positive anomaly of $T_{\max }$, a dry condition with precipitation anomaly of about $-6 \mathrm{~mm} \mathrm{day}^{-1}$ during the HW events is detected (Fig. 5d). In accordance with an upper-tropospheric convergence (i.e., positive anomalies of velocity potential at $200 \mathrm{hPa}$ )
(Fig. 5e) and a lower-tropospheric divergence indicated by negative anomalies at $850 \mathrm{hPa}$ (Fig. 5f) before and during the HW events, the anomalous subsidence of about $3 \times 10^{-4} \mathrm{hPa} \mathrm{s}^{-1}$ occurs during the HW events (Fig. $5 \mathrm{~g}$ ). The subsidence not only can induce the negative specific humidity anomaly at $850 \mathrm{hPa}$ (Fig. 5h), but also can increase the solar radiation at the surface (Fig. 5i) and increase the surface temperature (Fig. 5b). Because the surface temperature is larger than 2-m air temperature (Figs. 5a,b), it provides positive sensible heat flux from surface to air (Fig. 5j) and hence increases the surface air temperature. In addition, HW events are

TABLE 1. The number of cases used in composite analysis for the evolution of HW events in CA_S/CA_N. The notation is as follows: $\mathrm{ds}-0$ denotes the day when $\mathrm{HW}$ events begin, $\mathrm{ds}-1(+1)$ denotes one day before (after) ds -0 ; d-avg denotes the average between the beginning and end of HW events; de +0 denotes the day when HW events end, de +1 denotes one day after the end of HWs, and so on.

\begin{tabular}{lcccc}
\hline \hline $\mathrm{ds}-5$ & $\mathrm{ds}-4$ & $\mathrm{ds}-3$ & $\mathrm{ds}-2$ & $\mathrm{ds}-1$ \\
\hline $57 / 174$ & $61 / 181$ & $63 / 188$ & $65 / 198$ & $69 / 204$ \\
$\mathrm{ds}-0$ & $\mathrm{ds}+1$ & $\mathrm{ds}-\mathrm{avg}$ & $\mathrm{de}-1$ & $\mathrm{de}+0$ \\
\hline $69 / 204$ & $69 / 204$ & $69 / 204$ & $69 / 204$ & $69 / 204$ \\
$\mathrm{de}+1$ & $\mathrm{de}+2$ & $\mathrm{de}+3$ & $\mathrm{de}+4$ & $\mathrm{de}+5$ \\
\hline $69 / 204$ & $65 / 198$ & $63 / 188$ & $61 / 181$ & $57 / 174$ \\
\hline
\end{tabular}




\section{CA_S (0-7N, 15-30E)}

a) Tmax

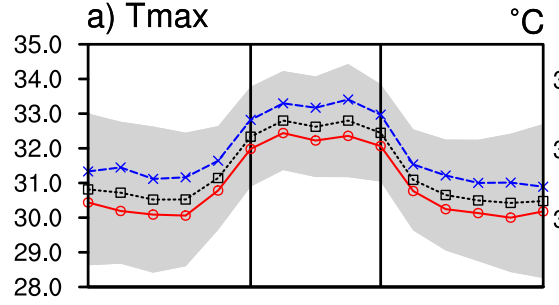

d) $\mathrm{Pr}$
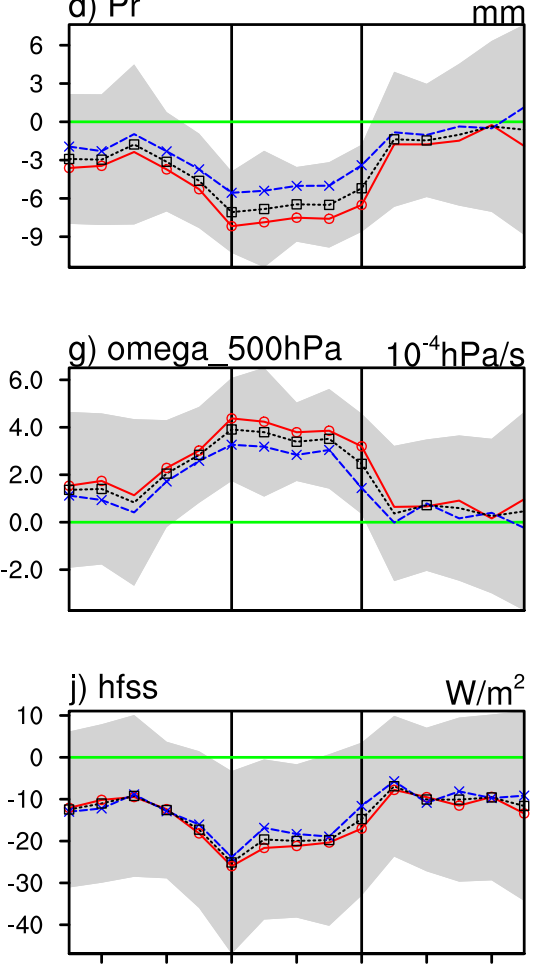

ds-4 ds-2 ds-0 d-avg de- 0 de+2de+4

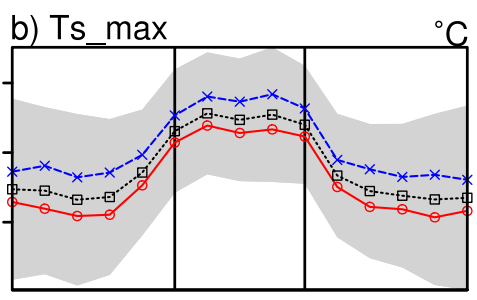

e) VP $200 \mathrm{hPa}$

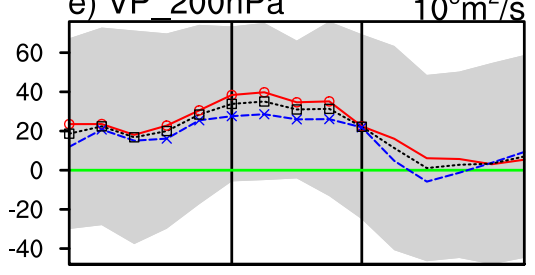

h) $\mathrm{q} 850 \mathrm{hPa}$

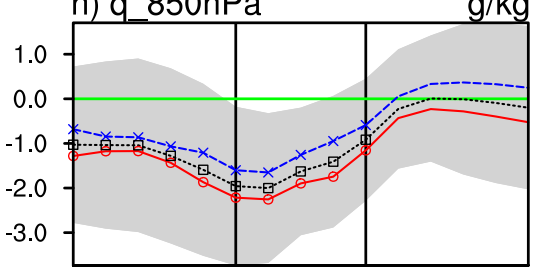

k) v_10m

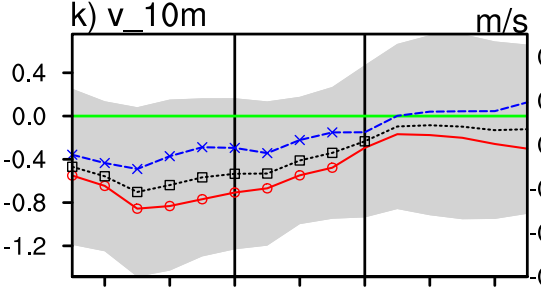

ds-4 ds-2 ds-0 d-avg de- 0 de+2de+4
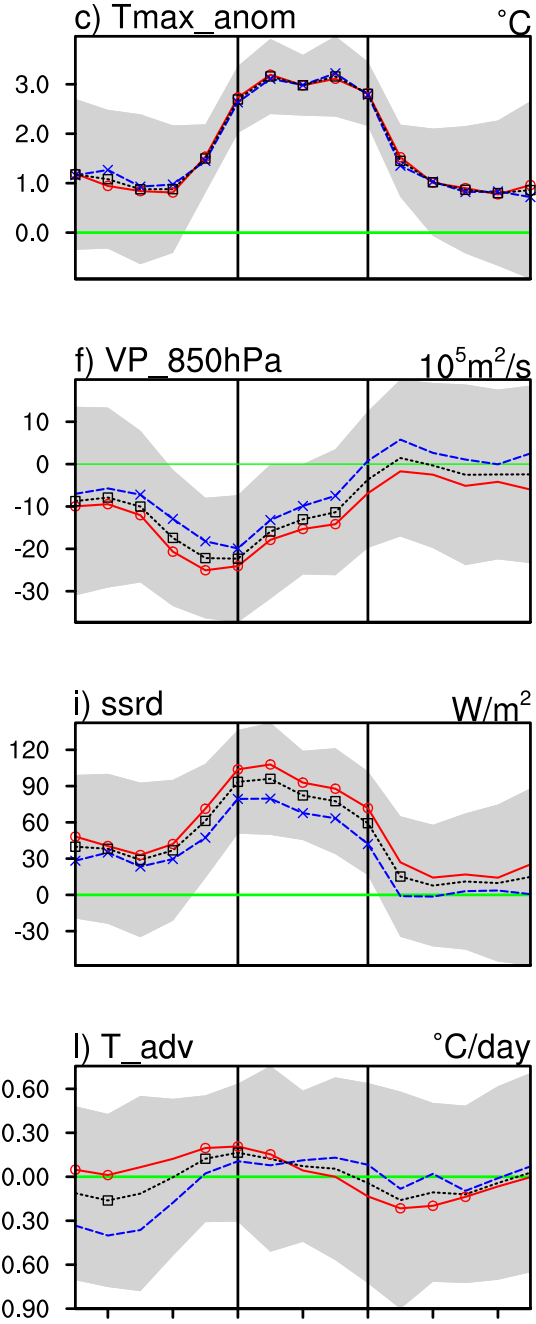

ds-4 ds-2 ds-0 d-avg de- 0 de $+2 d e+4$

FIG. 5. Evolution of the composite of the (a) maximum air temperature and (b) maximum surface temperature, and anomalous (c),(d) maximum air temperature and precipitation, (e),(f) velocity potential at 200 and $850 \mathrm{hPa}$, (g) vertical velocity at $500 \mathrm{hPa}$, (h) specific humidity at $850 \mathrm{hPa}$, (i) surface solar radiation, (j) downward sensible heat flux, (k) meridional wind at $10 \mathrm{~m}$, and (l) horizontal temperature advection during the period from 5 days before to 5 days after the HW events in the CA_S. Note that ds -0 denotes the day when HW events begin, ds $-1(+1)$ denotes one day before (after) ds -0 ; de +0 denotes the day when HW events end, de +1 denotes one day after the end of HW events, and so on. Red, blue, and black lines indicate the composite based on 1979-2000, 2001-16, and 1979-2016, respectively, and the markers denote significance at the $95 \%$ confidence level according to the Student's $t$ test. Light gray shading indicates the spread (i.e., \pm 1 standard deviation) of the cases during 1979-2016.

also partly attributed to a northerly wind anomaly of $-0.4 \mathrm{~m} \mathrm{~s}^{-1}$ (Fig. 5k) that brings about a weak warm advection anomaly of $0.1^{\circ} \mathrm{Cday}^{-1}$ at the beginning of HW events despite large spread among the events (Fig. 51). The anomalous northerly wind and the warm temperature advection decrease gradually afterward.

Most of the features associated with the heat wave events in CA_S show a signal before the event, but not after, with a quick transition to neutral conditions, especially the velocity potential at 200 (Fig. 5e) and $850 \mathrm{hPa}$ (Fig. 5f), vertical velocity at $500 \mathrm{hPa}$ (Fig. 5g), and specific humidity at $850 \mathrm{hPa}$ (Fig. 5h). Most fields return to around zero soon after the heat wave events, suggesting that the evolution of HW event is asymmetric and these events have little downstream effect or ability to precondition other events.

Figure 6 shows the evolution of velocity potential and divergent wind at 850 and $200 \mathrm{hPa}$, vertical velocity at 
$500 \mathrm{hPa}$, and a latitude-altitude cross section of wind between $15^{\circ}$ and $30^{\circ} \mathrm{E}$, associated with the HW events in the CA_S. Composite maps in Fig. 6 are shown from top to bottom for the days from ds -3 to de +1 . As shown in Fig. 6, a prominent convergence center in the upper troposphere and a divergence center in the lower troposphere appear in the north of CA_S (around $25^{\circ} \mathrm{N}$ ) during three and two days before the HW events onset ( $d s-3$ and ds -2 ). This is associated with downward air motion over the north of CA_S, with the greatest subsidence occurring between 500 and $400 \mathrm{hPa}$. On one day before the HW events $(\mathrm{ds}-1)$, the upper troposphere convergence center split into two centers (Fig. 6, second column). Its southern center becomes dominant with a regional subsidence center occurring over the CA_S. The southern center then intensifies and reaches a peak on the day of HW events beginning (ds -0 ), accompanying by a strong subsidence from $700 \mathrm{hPa}$ to the upper troposphere (fourth column in Fig. 6). Afterward, the anomalous upper-troposphere convergence and whole column subsidence over the CA_S weaken (ds-avg, defined in Table 1) and diminish in the following days, as the system moves gradually eastward (de +0 ; de +1$)$.

Figure 7 shows the evolution of near-surface anomalies, including the (from left to right) $T_{\max }$ anomaly, surface pressure anomaly, daily mean surface air temperature, and $10-\mathrm{m}$ wind anomaly, and precipitation anomaly. The results depict strong localized features with the warm $T_{\max }$ anomaly in the CA_S accompanied by a cold $T_{\max }$ anomaly at north of CA_S, especially before the occurrence of HW events (from ds -3 to ds -1 ). The evolution features of the $T_{\max }$ anomaly and precipitation anomaly are similar in the CA_S, as a warm $T_{\max }$ anomaly and a dry anomaly rapidly strengthen from ds -2 to ds -0 , and persist during the HW events. Finally, these anomalies decrease dramatically after the end of HW events $(\mathrm{de}+1)$. The evolution of anomalous $T_{\max }$ and precipitation are associated with the warm and dry air column above CA_S, resulting from the anomalous upper-troposphere convergence and whole column subsidence. The persisting negative precipitation anomaly leads to the negative soil moisture anomaly, which is conducive to the occurrence of heat wave through increasing sensible heat flux and reducing latent heat flux (Lorenz et al. 2010; Alexander 2011; Perkins 2015). In addition, there is a positive surface pressure anomaly in the north of CA_S from ds -3 to ds -0 . Because the maximum mean temperature locates around $10^{\circ} \mathrm{N}$, the anomalous northerly wind induced by the surface anomalous anticyclone brings a weak warm advection to CA_S.
For HW events in CA_S, the occurrences of an anomalous convergence center in the upper troposphere and divergence center in the lower troposphere induce strong subsidence anomalies, which leads to warming through greater solar insolation. Meanwhile, small amount of significant warm advections associated with HW events across the entire period are found from ds -1 to ds +1 (Fig. 5l). Therefore, the enhanced solar radiation induced by strong subsidence anomalies is the major contribution to the occurrences of HW events over CA_S, while anomalous temperature advection is the minor contribution.

\section{b. $C A \_N$}

In CA_N, HW events in the two decadal epochs before and after 2000 are composited together, in terms of the similar composite evolution features of the $T_{\max }, T_{s}$, $T_{\max }$ anomaly, and anomalous pertinent variables between the two epochs (Fig. 8). As shown in Fig. 8c, the $T_{\max }$ anomaly is $0.60^{\circ} \mathrm{C}$ at ds -5 and slowly increases to $1.11^{\circ} \mathrm{C}$ at ds -2 . Then the anomalous $T_{\max }$ rapidly increases to $2.51^{\circ} \mathrm{C}$ at the beginning of $\mathrm{HW}$ events. After the end of HW events, the anomaly decreases dramatically to $1.51^{\circ} \mathrm{C}$ at de +1 and then slowly decreases to $0.50^{\circ} \mathrm{C}$ at de +5 .

A negative anomaly of precipitation of about $-3 \mathrm{~mm} \mathrm{day}^{-1}$ is detected during the HW events (Fig. 8d). An anomalous subsidence of about $1.5 \times 10^{-4} \mathrm{hPa} \mathrm{s}^{-1}$ (Fig. 8g) occurs before and during the HW events, especially at ds -1 , ds -0 , and ds +1 , which is associated with the anomalous convergence at the upper troposphere (Fig. 8e) and divergence at the lower troposphere (Fig. 8f). Associated with the downward air motion, temperature is increased through positive anomalous solar radiation at the surface (Fig. 8i). Since the surface temperature is increased due to the positive solar radiation anomaly and is larger than the 2-m air temperature (Figs. 8a,b), more sensible heat flux is released from the surface to the air (Fig. 8j). The HW events are accompanied by an anomalous southerly wind, which increases gradually during the HW events and reaches a peak of $0.4 \mathrm{~m} \mathrm{~s}^{-1}$ at de -0 , whereas an anomalous warm advection occurs with a peak value of $0.42^{\circ} \mathrm{Cday}^{-1}$ at ds -0 , and then decreases gradually during the HW events. Hence, the evolutions between the anomalous southerly wind and the warm advection during the HW events are opposite, suggesting that the anomalous southerly wind is not the dominant factor responsible for the anomalous warm advection in the CA_N.

Compared to the evolution of the pertinent variables associated with HW events in the CA_S (Fig. 5), the magnitudes of anomalous precipitation, velocity 
VP \& Dwind 850hPa
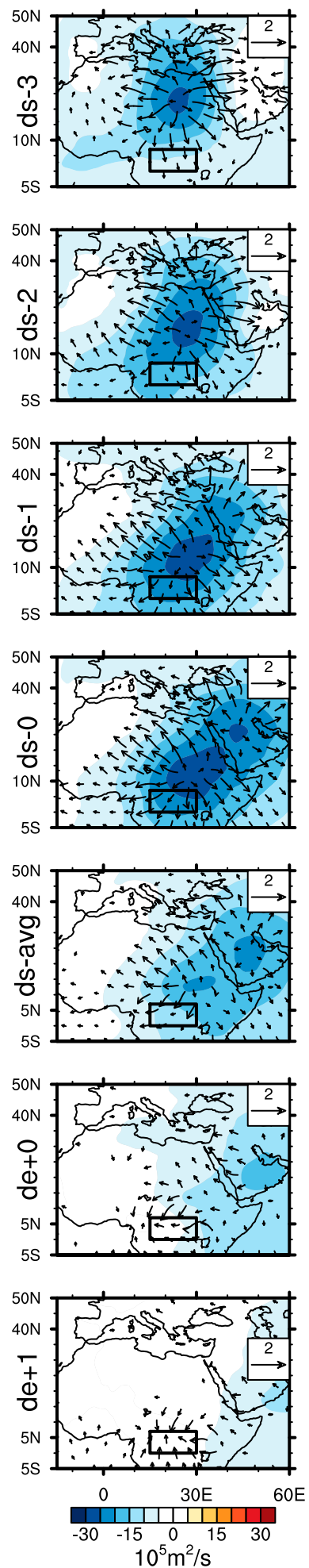
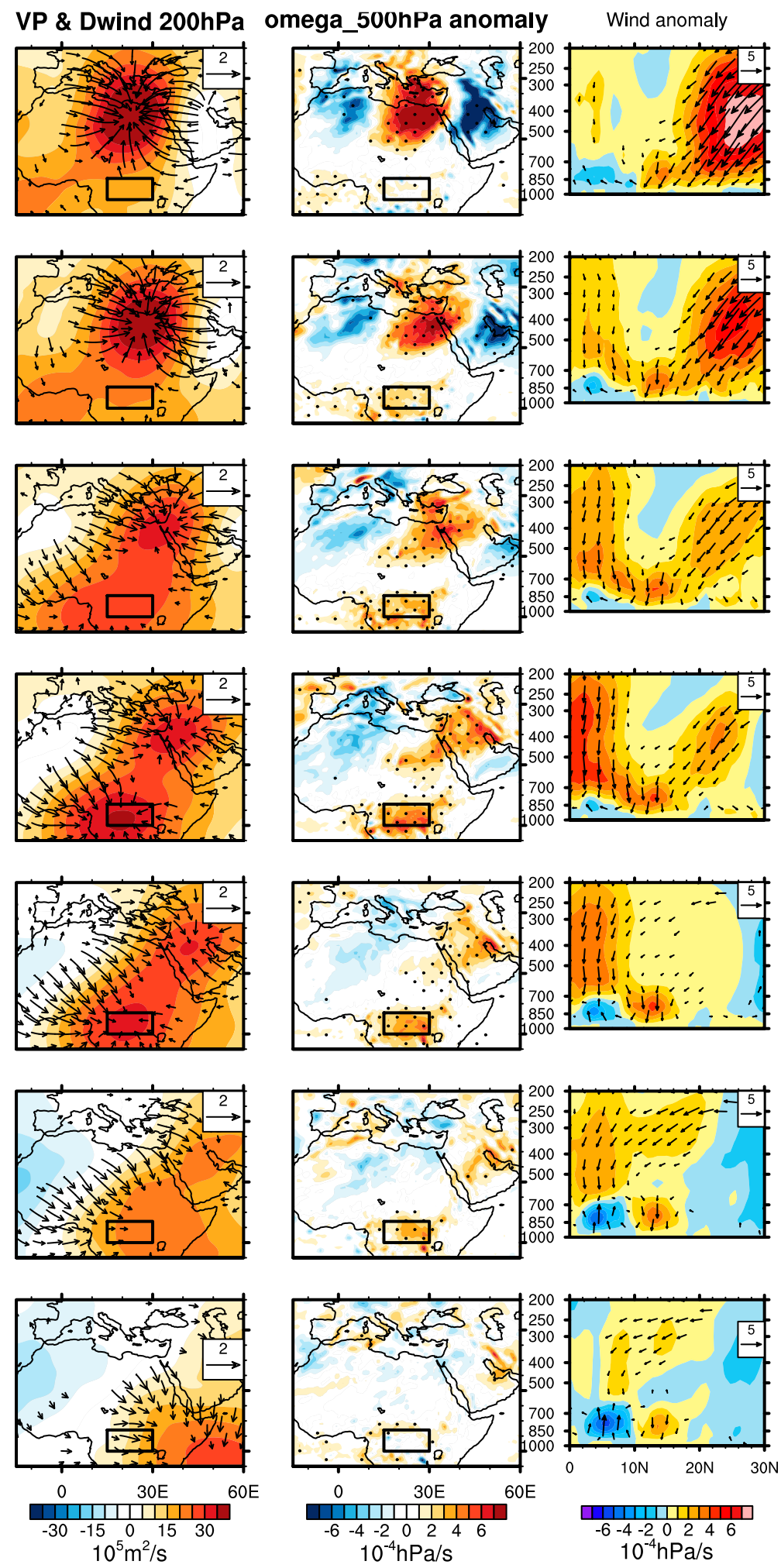

FIG. 6. Composite maps of the evolution of (first and second columns) anomalous velocity potential (shading) and divergent wind at 850 and $200 \mathrm{hPa}$, respectively, (third column) anomalous vertical velocity at $500 \mathrm{hPa}$, and (fourth column) vertical-meridional cross sections of anomalous winds from 1000 to $200 \mathrm{hPa}$ of the $15^{\circ}-30^{\circ} \mathrm{E}$ and vertical velocity (filled contours) before, during, and after the occurrence of HW events in the CA_S. Here, ds - 0 denotes the 
potential at 200 and $850 \mathrm{hPa}$, subsidence at $500 \mathrm{hPa}$, specific humidity at $850 \mathrm{hPa}$, surface solar radiation, and downward sensible heat flux are smaller in the CA_N. But the value of anomalous horizontal temperature advection is larger in the CA_N than in the CA_S. Otherwise, anomalous features associated with HW event tend to last longer in the CA_N than in the CA_S.

Figure 9 shows the evolution of velocity potential and divergent wind at 850 and $200 \mathrm{hPa}$, vertical velocity at $500 \mathrm{hPa}$, and a latitude-altitude cross section of wind between $15^{\circ}$ and $30^{\circ} \mathrm{E}$, associated with the HW events in the CA_N. Composite maps in Fig. 9 are displayed from top to bottom for the days from ds -3 to de +1 . A dipole pattern of a large negative velocity potential anomaly in the northwest and a large positive anomaly in the southeast at $200 \mathrm{hPa}$ occurs at ds -3 and strengthens gradually from ds -3 to ds -0 ; especially the positive anomalous velocity potential (i.e., convergence) becomes stronger (Fig. 9, second column). After the occurrence of HW events, the dipole pattern migrates toward the east with the negative anomalous velocity potential getting stronger. The evolution of the anomalous velocity potential and divergent wind at 850 and $200 \mathrm{hPa}$ induces the evolution of vertical air motion. A dipole pattern of an anomalous ascent motion mainly around the Mediterranean and subsidence from the Arabian Peninsula to CA_N exists at ds -3 . The dipole pattern of the anomalous subsidence intensifies gradually and reaches a peak at ds -0 , and then becomes weak and moves eastward from ds-avg to de +1 . At ds -0 (Fig. 9, third column), an anomalous subsidence center at $500 \mathrm{hPa}$ appears in the CA_N with the largest downward air motion between 500 and $400 \mathrm{hPa}$ (Fig. 9, fourth column). This subsidence center weakens and diminishes in the following days.

Figure 10 shows the evolution of near-surface anomalies associated with the HW events in $\mathrm{CA}$-N, including the (from left to right) wind at $10 \mathrm{~m}$ and anomalous $T_{\max }$, surface pressure anomaly, daily mean temperature and anomalous wind at $10 \mathrm{~m}$, and precipitation anomaly. Over the Mediterranean, an anomalous cyclone associated with the anomalous divergence in the upper troposphere and convergence in the lower troposphere occurs at ds -3 and strengthens gradually from $\mathrm{ds}-3$ to $\mathrm{ds}-1$. Because the maximum mean temperature is located near $10^{\circ} \mathrm{N}$ (figure not shown), the anomalous southerly wind induced by the anomalous cyclone brings an anomalous warm advection to the north of CA_N. Hence, positive $T_{\max }$ anomalies in the north of CA_N are larger than those in the CA_N during the days from ds -3 to ds -0 (Fig. 10, first column). Based on this anomalous temperature gradient before and in the beginning of HW events, an anomalous warm advection is transported from north to $\mathrm{CA}$-N by the mean northerly wind. As the anomalous cyclone weakens and migrates eastward from ds-avg to de +1 , an anomalous northerly wind occurs, and hence there is no warm advection anomaly in the north of CA_N. Meanwhile, associated with the increasing $T_{\max }$ anomaly in the CA_N, an anomalous temperature gradient between the north and CA_N decreases after the onset of HW events, and thus the anomalous warm advection decreases gradually during the HW events. This is consistent with the evolution of horizontal anomalous temperature advection (Fig. 81). In addition, the evolution of the negative precipitation anomaly in the CA_N is associated with the warm and dry air column, resulting from the anomalous subsidence and upper-troposphere convergence.

The occurrence of HW events in the CA_N is partly attributed to the positive solar radiation anomaly at the surface due to the subsidence induced by the anomalous convergence in the upper troposphere and divergence in the lower troposphere. Associated with the anomalous temperature gradient between the CA_N and the area to its north resulting from the anomalous cyclone in the north, the anomalous warm advection associated with mean northerly wind plays an important role in the evolution of the positive $T_{\max }$ anomaly in the CA_N, especially before and at the beginning of the HW events.

In addition, both the intensity and pattern of the anomalous convergence in the upper troposphere are different during the HW events over CA_S (Fig. 6, second column) and over CA_N (Fig. 9, second column). There is an anomalous convergence center over CA_S when HW events occur, whereas no anomalous convergence occurs during the CA_N HW events. In addition, the anomalous velocity potential shows a uniform pattern when HWs occur over CA_S, in contrast to the dipole pattern in the CA_N HW events.

For the HW events in CA_S, Fig. 7 (first column) indicates that positive $T_{\max }$ anomalies dominate the CA_S

day when HW events begin, ds $-1(+1)$ denotes one day before (after) ds -0 ; de +0 denotes the day when HW events end, de +1 denotes one day after the end of HW events, and so on. The thick black rectangle denotes the location of CA_S. Dots denote significance at the 95\% confidence level according to the Student's $t$ test. For the winds, black vectors indicate that either the zonal (vertical) or meridional wind anomaly is significant. 
Tmax anomaly
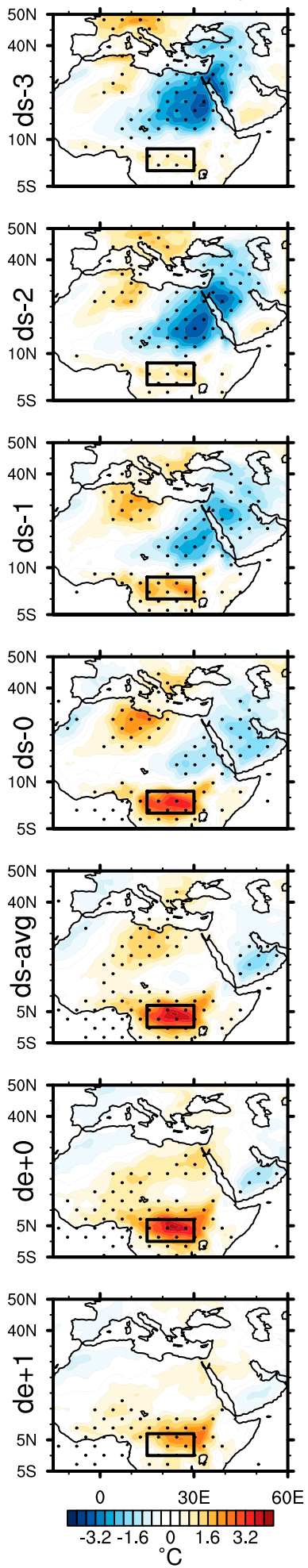

Ps anomaly
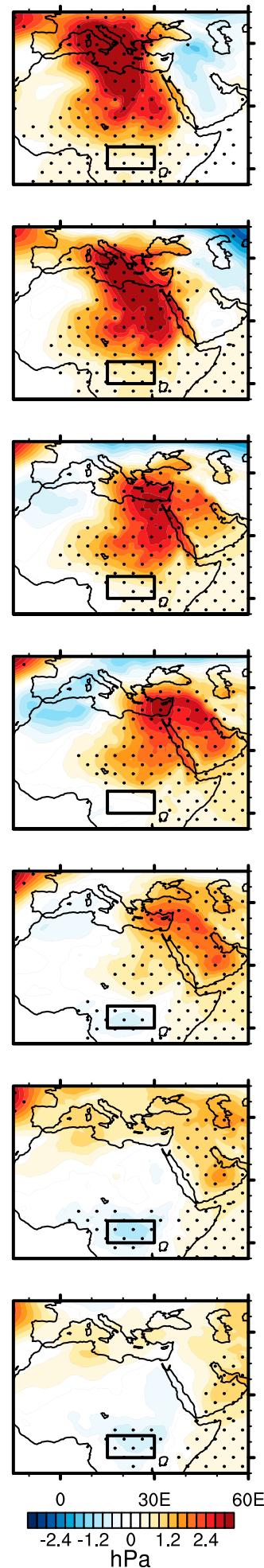

Tmean \& Wind $10 \mathrm{~m}$ anomaly
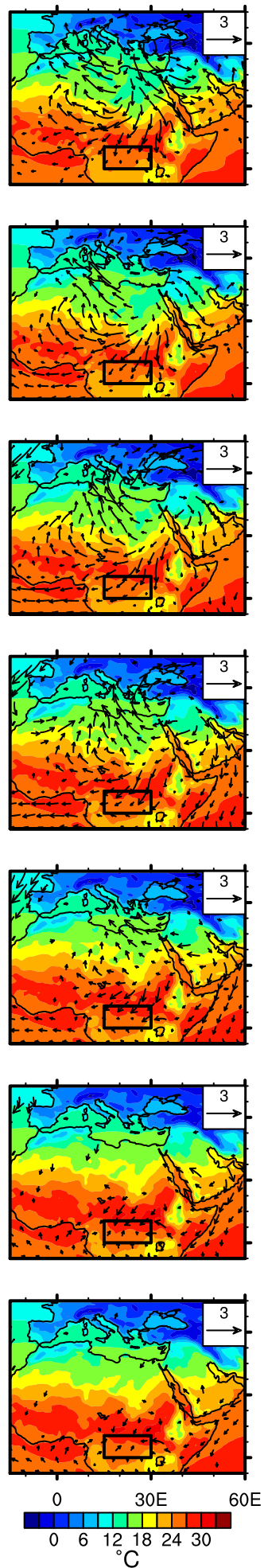

Pr anomaly
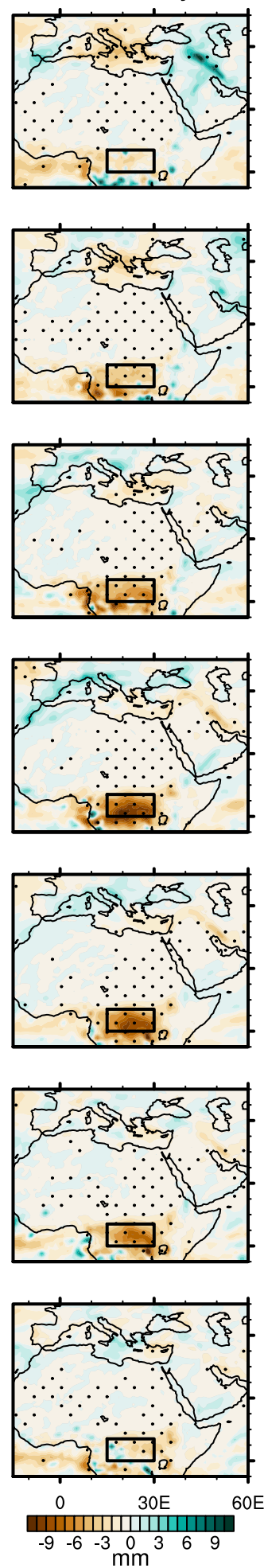

FIG. 7. As in Fig. 6, but for composite maps of the evolution of (from left to right) anomalous $T_{\max }$, anomalous surface pressure, $T_{\text {mean }}$ (shading) and anomalous 10-m wind, and anomalous precipitation before, during, and after the occurrence of HWs in the CA_S. For the winds, black vectors indicate that either the zonal or meridional wind anomaly is significant. 


\section{CA_N (7-15N, 15-30E)}

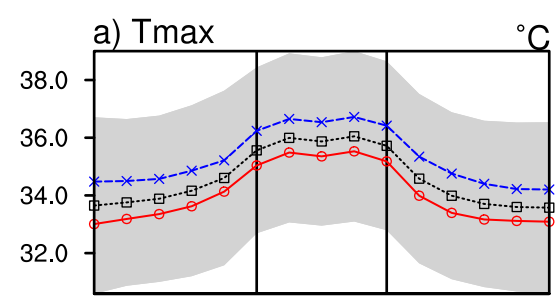

b) Ts_max

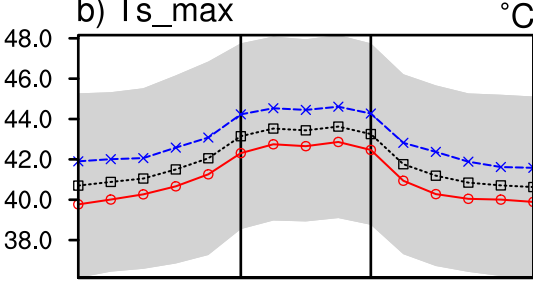

d) $\operatorname{Pr}$

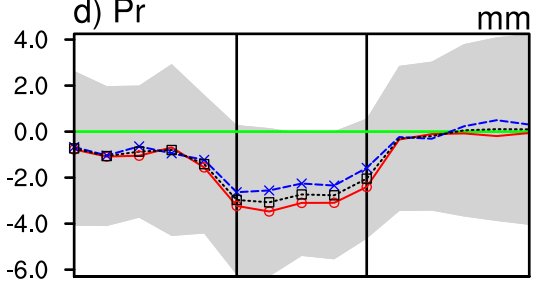

g) omega $500 \mathrm{hPa} \quad 10^{-4} \mathrm{hPa} / \mathrm{s}$
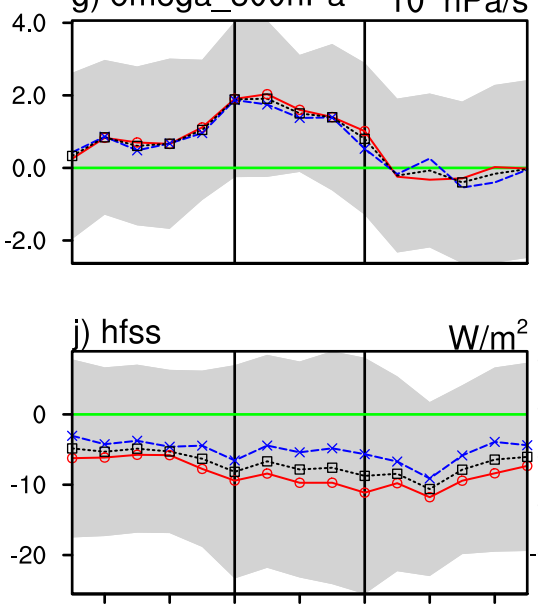

ds-4 ds-2 ds-0 d-avg de-0 de+2de+4
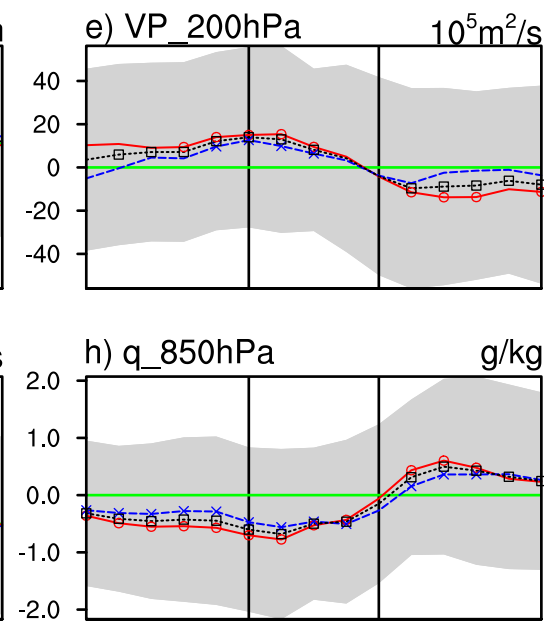

h) $\mathrm{q} 850 \mathrm{hPa}$

k) v $10 \mathrm{~m}$

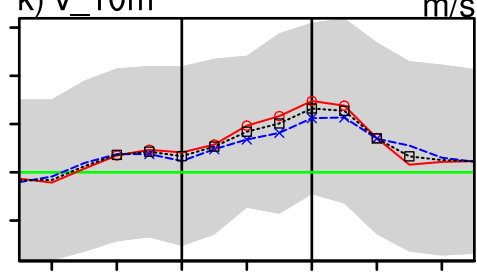

ds-4 ds-2 ds-0 d-avgde-0 de+2de+4

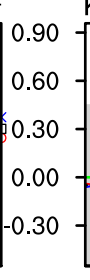

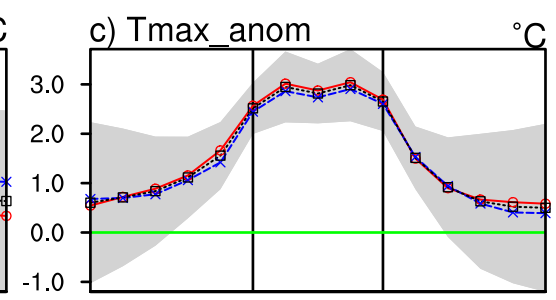
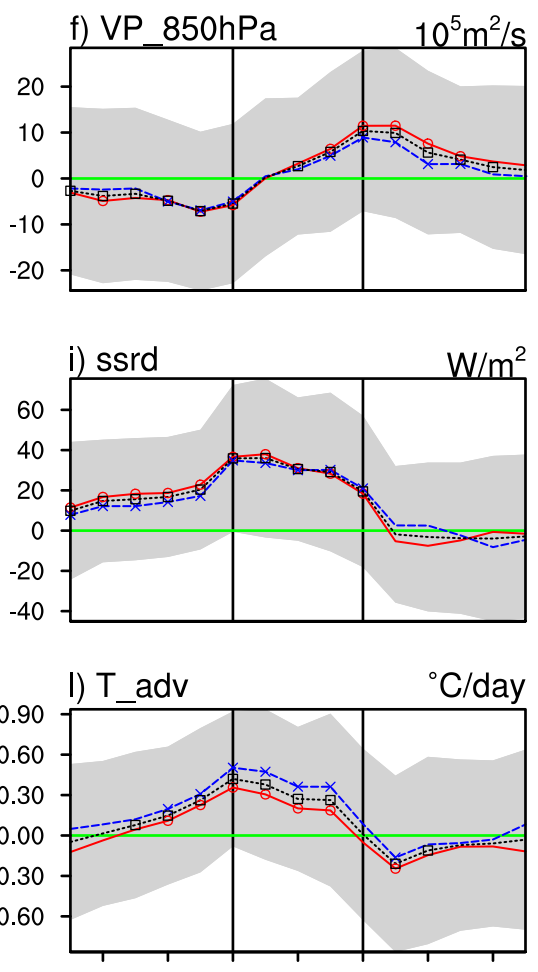

ds-4 ds-2 ds-0 d-avg de- 0 de+2de+4

FIG. 8. As in Fig. 5, but for the composite results of the HW events in CA_N and the difference in the $y$ axes.

with negative or neutral $T_{\max }$ anomalies over CA_N . For HW events in CA_N, Fig. 10 (first column) shows that positive $T_{\max }$ anomalies occur over CA_N and north of CA_N with neutral anomalies over CA_S. Therefore, the level of concomitance between the heat wave occurrences over CA_S and CA_N is low, which is consistent with the results from the EOF analysis of deseasonalized time series of $T_{\max }$.

\section{Factors contributing to the magnitude of HWs}

We have illustrated the evolution of synoptic features associated with the HW events occurring in the CA_S and $\mathrm{CA} \_\mathrm{N}$ in the previous section. Because the magnitude of the HW events is one of the most important aspect of the HW activity and exerts notable influences on both socioeconomic and public health, it is important to explore dominant factors that influence the magnitude of the HW events.

As listed in Table 2, for the HW events during both $\mathrm{p} 1$ (1979-2000) and p2 (2001-16) in the CA_S, correlation coefficients between the $T_{\max }$ anomaly and the anomaly of 500-hPa omega (omega_500 hPa), surface solar radiation (ssrd), surface temperature $\left(T_{s}\right)$, and downward sensible heat flux (hfss) are statistically significant at the $95 \%$ confidence level according to the Student's $t$ test. In contrast, anomaly correlation coefficients between $T_{\max }$ and the $10-\mathrm{m}$ meridional wind ( $\left.\mathrm{v} \_10 \mathrm{~m}\right)$ and horizontal temperature advection ( $\mathrm{T}_{-} \mathrm{adv}$ ) are small and insignificant. Note that concerning the HW events in the CA_N, as shown in the previous section, anomalous wind is not the cause for the anomalous temperature 
VP \& Dwind 850hPa
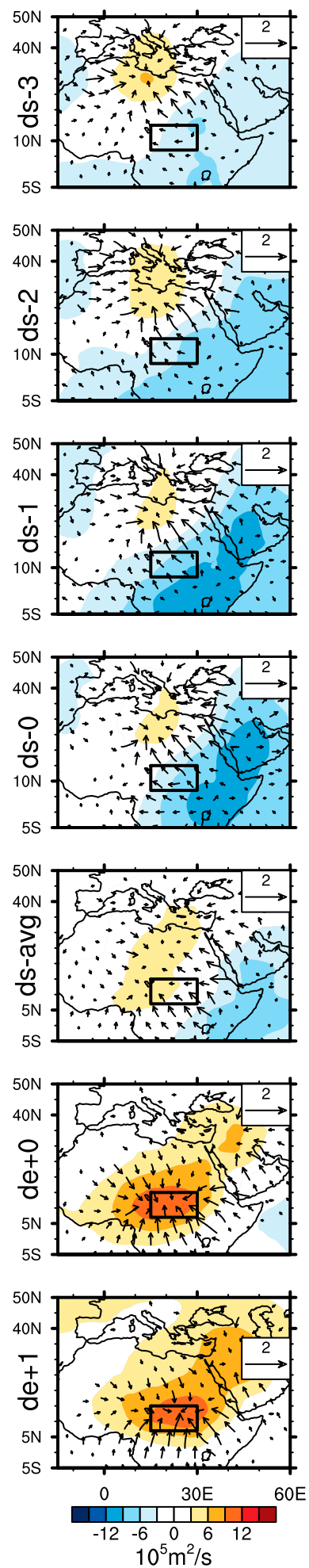
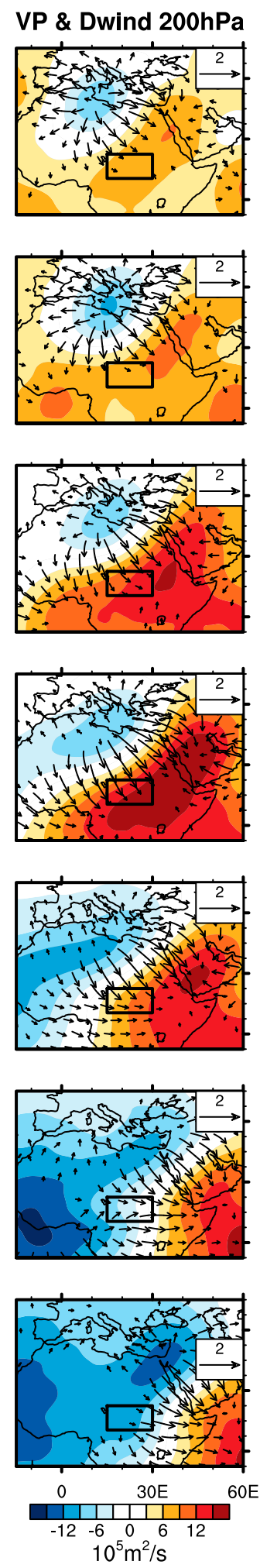

Wind anomaly
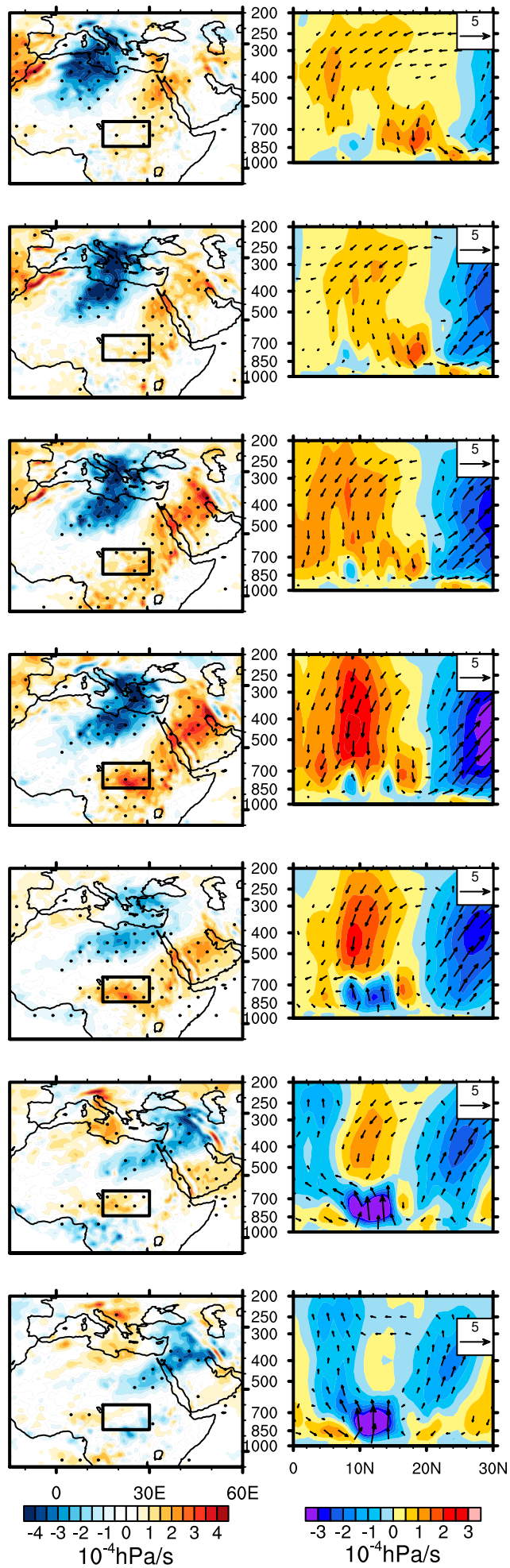

FIG. 9. As in Fig. 6, but for the results of HW events in CA_N. 

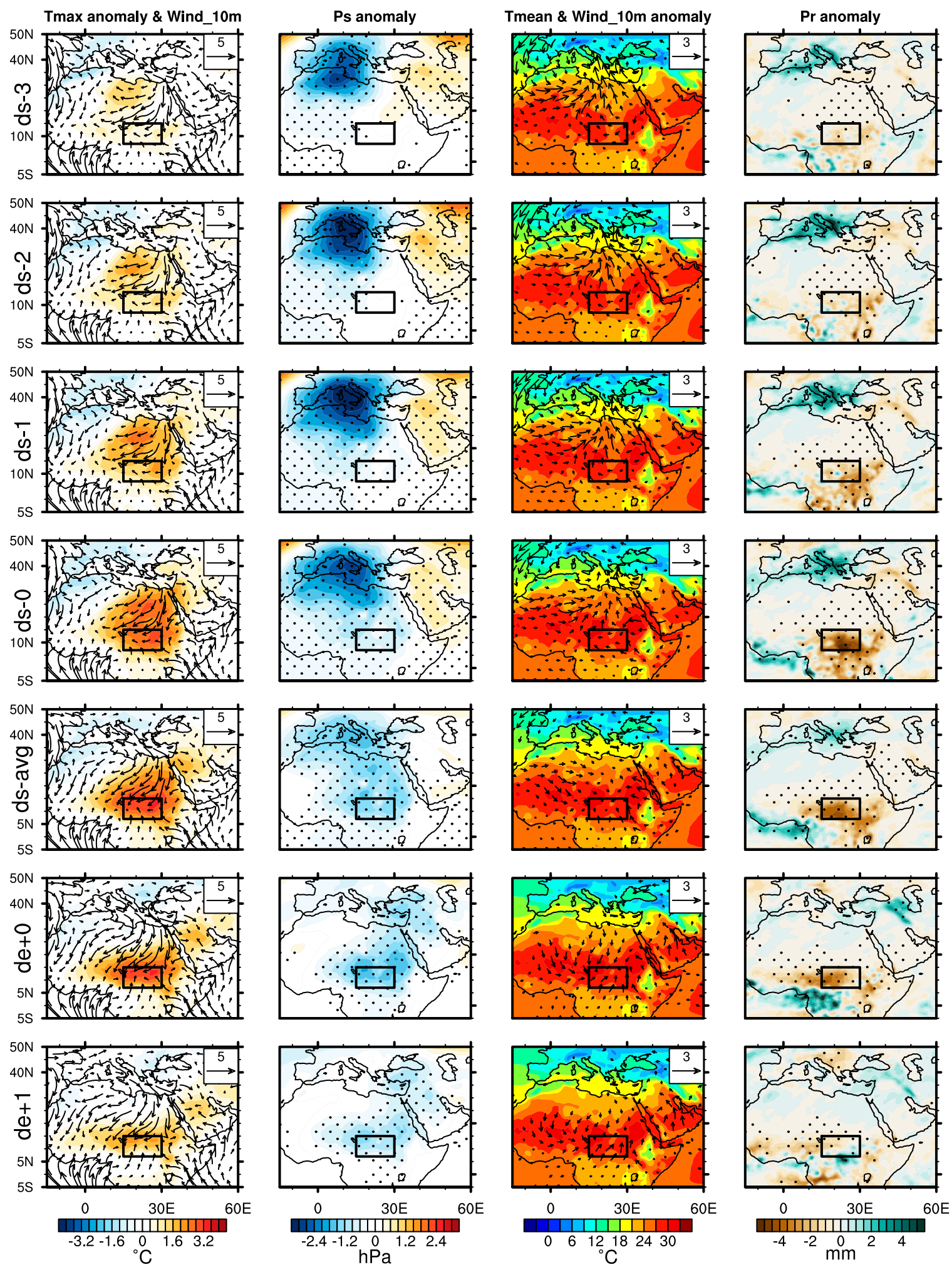

FIG. 10. As in Fig. 6, but for composite maps of the evolution of (from left to right) wind at $10 \mathrm{~m}$ and anomalous $T_{\max }$, anomalous surface pressure, $T_{\text {mean }}$ (shading) and anomalous $10-\mathrm{m}$ wind, and anomalous precipitation before, during, and after the occurrence of HWs in the CA_N. 
TABLE 2. Correlation coefficients (CCR) between the anomalies of $T_{\max }$ and v_10m, T_adv, omega_500 hPa, ssrd, $T_{\mathrm{s}}$, and hfss during HWs for the two decadal epochs (p1 vs p2). An asterisk (*) indicates statistical significance at the $95 \%$ confidence level according to the Student's $t$ test.

\begin{tabular}{ccccccc}
\hline \hline CCR & v_10m & T_adv & omega_500 hPa & ssrd & $T_{s}$ & hfss \\
\hline CA_S p1 & -0.25 & 0.18 & $0.42^{*}$ & $0.47^{*}$ & $0.48^{*}$ & $-0.77^{*}$ \\
CA_S p2 & -0.23 & 0.09 & $0.42^{*}$ & $0.46^{*}$ & $0.50^{*}$ & $-0.65^{*}$ \\
CA_N p1 & $0.30^{*}$ & $0.29^{*}$ & -0.10 & -0.02 & $0.61^{*}$ & -0.10 \\
CA_N p2 & $0.42^{*}$ & $0.51^{*}$ & -0.13 & -0.06 & $0.77^{*}$ & -0.08 \\
\hline
\end{tabular}

advection, so it does not make sense to discuss the correlation coefficients between anomalous $\mathbf{v} \_10 \mathrm{~m}$ and $T_{\max }$. The results show that the anomaly correlation coefficient between $T_{\max }$ and $T_{-}$adv is significant; the correlations with other variables are insignificant. This indicates that the main factors responsible for the magnitude of HW events in the CA_S and CA_N are different.

For HW events in the CA_S during the period 19792016, a statistically significant positive correlation (with a correlation coefficient of 0.42 ) between the $T_{\max }$ anomaly and the 500 -hPa vertical velocity anomaly is found for all years, indicating that the intensity of HW events increases with stronger subsidence. Since surface solar radiation is enhanced by subsidence, there is also a positive correlation coefficient of 0.46 between $T_{\max }$ and the surface solar radiation anomaly. Solar radiation increases surface temperature directly and then raises air temperature indirectly through positive sensible heat fluxes from surface to air; this relation is reflected by the negative correlation coefficient of -0.71 between $T_{\max }$ and downward sensible heat flux. Hence, in the CA_S region, the magnitude of the HW events is associated with the intensity of the sensible heat flux released from the surface to the air due to increased surface temperature, which is affected directly by increasing surface solar radiation resulting from the stronger subsidence.

For HW events in the CA_N region, a positive correlation coefficient of 0.41 is seen between the anomalous $T_{\max }$ and temperature advection during the period 1979-2016, indicating that a large portion of the variance in the magnitude of HW events in CA_N is explained by anomalous warm advection. In the previous section, we have identified that the anomalous warm advection in CA_N is induced by the mean northerly wind of the anomalous temperature gradient between CA_N and areas north of there.

\section{Summary and discussion}

In this study, we have identified central Africa (CA) as a location with a strong multidecadal trend of extreme heat (EH) during 1979-2016 in the Northern Hemisphere. We examined the evolution of synoptic features associated with heat wave (HW) events in CA. The regional averaged
EH in CA depicts a strong multidecadal trend owing to a regime shift around the year 2000; no linear steady increase is observed. The results show that the HW-related circulation is characterized by an anomalous convergence in the upper troposphere and a divergence anomaly in the lower troposphere. In general, surface temperature is increased by enhanced solar radiation at surface due to the stronger subsidence, which is induced by an anomalous convergence at $200 \mathrm{hPa}$. Consequently, air temperature is heated by the positive sensible heat flux released from the surface to the air due to the increased surface temperature. However, distinctive features exist for the HW events in the southern and northern CA regions (CA_S and CA_N).

During the evolution before the occurrence of HW events in the CA_S, the upper-troposphere convergence anomaly occupies a broad area with a center appearing first in the north of CA_S; then the center splits into two centers with the southern one overlaying the CA_S region. Hence, the CA_S region is dominated by a strong subsidence anomaly, which enhances the insolation at the surface, thus increasing the surface temperature. In the CA_N, a dipole pattern with an anomalous convergence in the southeast and a divergence anomaly in the northwest occurs and gradually strengthens before the occurrence of HW events. The CA_N region is covered by a weak convergence anomaly without a convergent center. Therefore, the positive solar radiation anomaly at the surface associated with the anomalous subsidence is larger in the CA_S than that in the CA_N. These findings suggest that the subsidence associated with the anomalous convergence in the upper troposphere contributes to the occurrence of HW events, especially in the CA_S.

The horizontal flow also plays an important role in increasing the air temperature via warm temperature advection. Because the maximum mean temperature is located around $10^{\circ} \mathrm{N}$, the northerly wind anomaly induced by the surface anomalous anticyclone brings a weak anomalous warm advection to CA_S. Based on the anomalous temperature gradient between the CA_N and regions to its north, the anomalous warm advection by the mean northerly wind contributes to the positive $T_{\max }$ anomaly in the CA_N, especially at the beginning of HW events.

In the CA_S, the subsidence associated with the anomalous convergence in the upper troposphere is the 
climatology and trend of HDs \& HWs during 1979-2016 - BEST
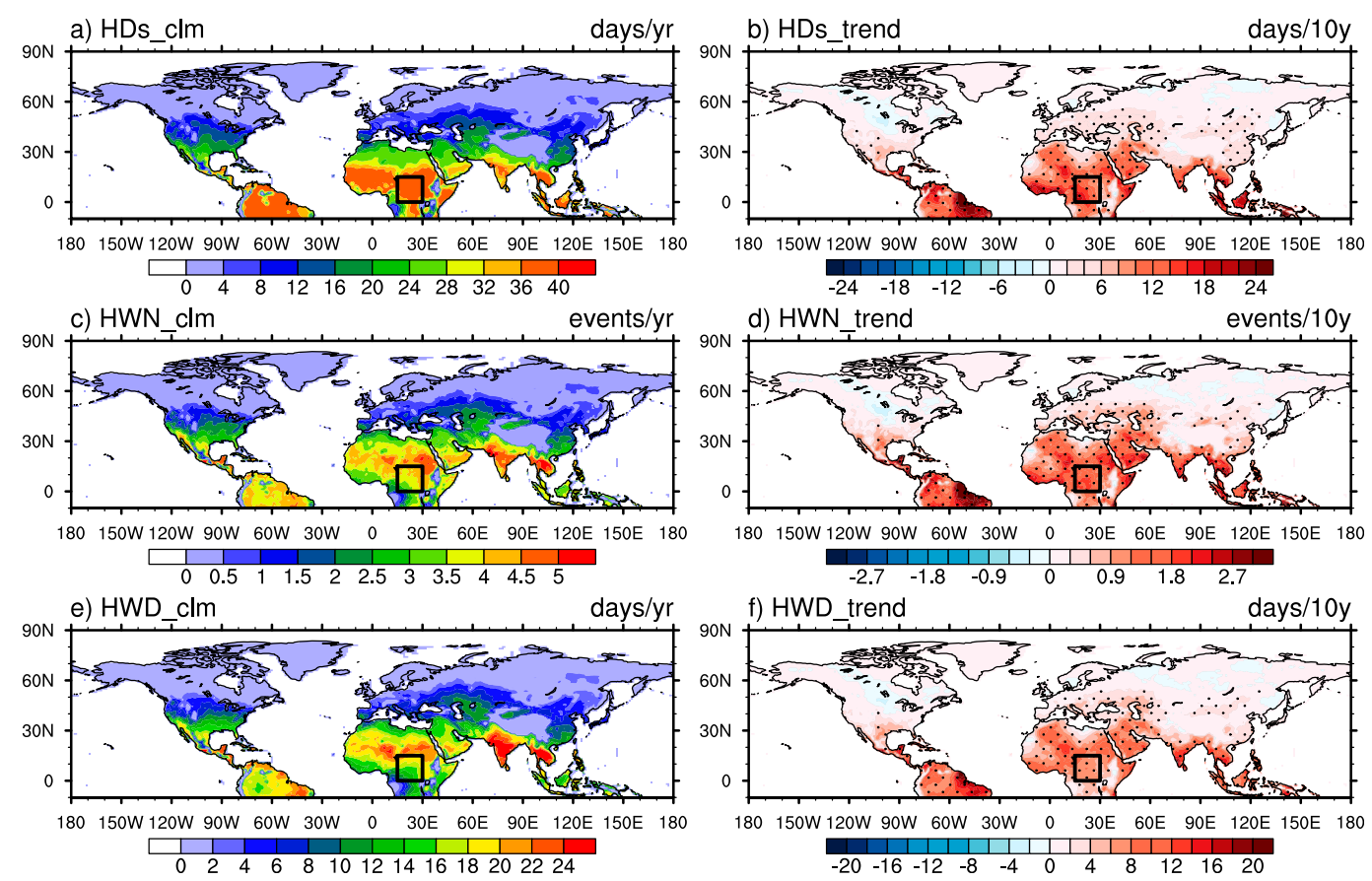

FIG. A1. Climatology and linear trend of (a),(b) HDs, (c),(d) HWN, and (e),(f) HWD during 1979-2016 derived from the BEST gridded data in North Hemisphere. Dots denote significance at the $95 \%$ confidence level according to the Student's $t$ test. Black boxes denote the CA region.

dominant factor in both the occurrence and magnitude of HW events. Surface temperature increases due to the increased solar radiation at surface; this leads to a higher air temperature due to the positive sensible heat flux anomaly released from surface to air. In CA_N, however, the occurrence of the HW events is subject to the combined effect of the warming associated with a weak subsidence and horizontal warm advection. The latter is induced by prevailing northerly wind acting on the anomalous temperature gradient, and the anomalous warm advection is a main factor responsible for the magnitude of the HW events in the CA_N.

Our work finds the synoptic features and circulation patterns responsible for heat wave events in CA, as well as the factors responsible for their magnitudes. Based on these results, we can utilize the circulation patterns that lead to heat wave events as predictors to improve the forecast skill to some extent.

Because the synoptic features associated with HW events are quite different in the two regions (i.e., CA_S and CA_N), the diversity and locality features should be paid attention to when analyzing the EH-related synoptic factors. Previous studies suggested that extreme heat and its variation can be affected by various processes (Stefanon et al. 2012; Chen and Lu 2015; Lu and Chen 2016; W. Wang et al. 2013; Wang et al. 2016).
Both the circulation anomalies and other factors such as urbanization and land-cover changes have been emphasized (Avila et al. 2012; M. Wang et al. 2013; Oleson et al. 2018; Luo and Lau 2017). For example, Luo and Lau (2017) investigated the urbanization effects on HW events in southern China, and found that the urbanization contributes to nearly $50 \%$ of the increase in HW frequency in the Pearl River delta region.

Previous studies indicated that high temperature weather can be classified into two types: extreme heat, which features a very high $T_{\max }$; and tropical nights, which feature an extremely high minimum temperature $T_{\min }$ (Wei and Sun 2007; Park et al. 2012; Lu and Chen 2016). Tropical nights have a significant impact on sleep comfort and inhibit a person's recovery from heat during daytime, thus increasing the threat of temperature extremes on human health (Yang et al. 2010). The processes controlling $T_{\max }$ and $T_{\min }$ are likely to be distinct ( $\mathrm{Lu}$ and Chen 2016): maximum temperature is often influenced by the incoming surface shortwave radiation whereas the minimum temperature is very sensitive to the amount of water vapor sometimes (Barbier et al. 2018). Hence, it is valuable to perform similar analyses based on tropical nights.

While public human health depends largely on temperature, other variables such as specific humidity, 


\section{Changes of HDs \& HWN \& HWD during 1979-2016 - BEST}
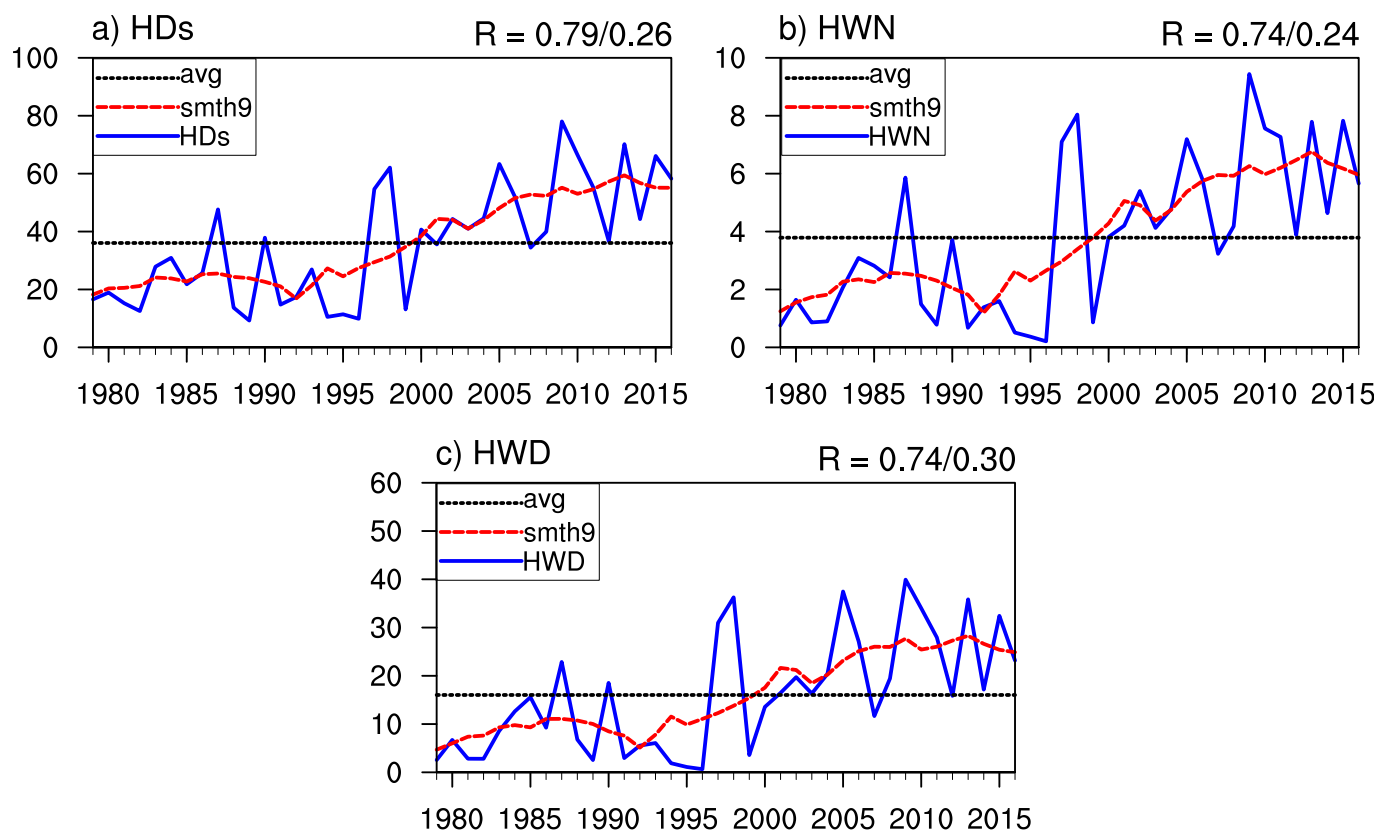

FIG. A2. Time series of the annual number of regionally averaged (a) HDs, (b) HWN, and (c) HWD (blue lines) in CA and their 9-yr moving mean (red lines) derived from the BEST gridded data. The $R$ represents the correlation coefficients between BEST and either ERA-Interim or NCEP2.

wind speed, and solar radiation are also important; human health is more severely influenced by the simultaneous occurrence of high temperature, high humidity, and weak wind (Robinson 2001; Epstein and Moran 2006; Blazejczyk et al. 2012; Pal and Eltahir 2016). Under hot conditions, high humidity reduces sweat evaporation from the human body needed for cooling, and hence consequently increases heat stress. Similarly, weak wind fails to remove heat due to small evaporation (Wu et al. 2017). Hot days and HW events are defined based on the temperature criterion in the present study. It is of great necessity to extend the definition of $\mathrm{EH}$ by combining temperature and the other pertinent variables in future studies.

Acknowledgments. This work was supported by the National Natural Science Foundation of China (41425019, 41831175, and 41721004) and the China scholarship council. Jing-Jia Luo is supported by "The Startup Foundation for Introducing Talent of NUIST."

\section{APPENDIX}

\section{Verify the Changes of Extreme Temperature from Observation Data}

Figure A1 shows the climatology and linear trend of HDs, HWN, and HWD derived from the BEST gridded data and verifies the results from ERA-Interim. Figure A2 displays times series of the annual number of regionally averaged HDs, HWN, and HWD in CA and the correlation coefficients between the BEST and the ERA-Interim/NCEP2, indicating that the ERA-Interim is better in capturing the features of extreme temperatures in CA than NCEP2.

\section{REFERENCES}

Alexander, L. V., 2011: Climate science: Extreme heat rooted in dry soils. Nat. Geosci., 4, 12-13, https://doi.org/10.1038/ngeo1045. _ , and Coauthors, 2013: Summary for policymakers. Climate Change 2013: The Physical Science Basis, T. F. Stocker et al., Eds., Cambridge University Press, 3-29.

Avila, F., A. Pitman, M. Donat, L. Alexander, and G. Abramowitz, 2012: Climate model simulated changes in temperature extremes due to land cover change. J. Geophys. Res., 117, D04108, https://doi.org/10.1029/2011JD016382.

Baccini, M., and Coauthors, 2008: Heat effects on mortality in 15 European cities. Epidemiology, 19, 711-719, https://doi.org/ 10.1097/EDE.0b013e318176bfcd.

Barbier, J., F. Guichard, D. Bouniol, F. Couvreux, and R. Roehrig, 2018: Detection of intraseasonal large-scale heat waves: Characteristics and historical trends during the Sahelian spring. J. Climate, 31, 61-80, https://doi.org/ 10.1175/JCLI-D-17-0244.1.

Barreca, A. I., 2012: Climate change, humidity, and mortality in the United States. J. Environ. Econ. Manage., 63, 19-34, https:// doi.org/10.1016/j.jeem.2011.07.004. 
— K. Klay, O. Deschenes, M. Greenstone, and J. S. Shapiro, 2016: Adapting to climate change: The remarkable decline in the US temperature-mortality relationship over the twentieth century. J. Polit. Econ., 124, 105-159, https://doi.org/10.1086/ 684582.

Blazejczyk, K., Y. Epstein, G. Jendritzky, H. Staiger, and B. Tinz, 2012: Comparison of UTCI to selected thermal indices. Int. J. Biometeor., 56, 515-535, https://doi.org/10.1007/ s00484-011-0453-2.

Chen, R., and R. Lu, 2015: Comparisons of the circulation anomalies associated with extreme heat in different regions of eastern China. J. Climate, 28, 5830-5844, https://doi.org/ 10.1175/JCLI-D-14-00818.1.

Coumou, D., and S. Rahmstorf, 2012: A decade of weather extremes. Nat. Climate Change, 2, 491-496, https://doi.org/ 10.1038/nclimate1452.

Curriero, F. C., K. S. Heiner, J. M. Samet, S. L. Zeger, L. Strug, and J. A. Patz, 2002: Temperature and mortality in 11 cities of the eastern United States. Amer. J. Epidemiol., 155, 80-87, https:// doi.org/10.1093/aje/155.1.80.

Dee, D. P., and Coauthors, 2011: The ERA-Interim reanalysis: Configuration and performance of the data assimilation system. Quart. J. Roy. Meteor. Soc., 137, 553-597, https://doi.org/ 10.1002/qj.828.

Deschênes, O., and E. Moretti, 2009: Extreme weather events, mortality, and migration. Rev. Econ. Stat., 91, 659-681, https:// doi.org/10.1162/rest.91.4.659.

Dole, R., and Coauthors, 2011: Was there a basis for anticipating the 2010 Russian heat wave? Geophys. Res. Lett., 38, L06702, https://doi.org/10.1029/2010GL046582.

Engelbrecht, F., and Coauthors, 2015: Projections of rapidly rising surface temperatures over Africa under low mitigation. Environ. Res. Lett., 10, 085004, https://doi.org/10.1088/1748-9326/ 10/8/085004.

Epstein, Y., and D. S. Moran, 2006: Thermal comfort and the heat stress indices. Ind. Health, 44, 388-398, https://doi.org/10.2486/ indhealth.44.388.

Fontaine, B., S. Janicot, and P.-A. Monerie, 2013: Recent changes in air temperature, heat waves occurrences, and atmospheric circulation in Northern Africa. J. Geophys. Res. Atmos., 118, 8536-8552, https://doi.org/10.1002/JGRD.50667.

García-Herrera, R., J. Díaz, R. Trigo, and E. Hernández, 2005: Extreme summer temperatures in Iberia: Health impacts and associated synoptic conditions. Ann. Geophys., 23, 239-251, https://doi.org/10.5194/angeo-23-239-2005.

Gershunov, A., D. R. Cayan, and S. F. Iacobellis, 2009: The Great 2006 Heat wave over California and Nevada: Signal of an increasing trend. J. Climate, 22, 6181-6203, https://doi.org/ 10.1175/2009JCLI2465.1.

Grumm, R. H., 2011: The central European and Russian heat event of July-August 2010. Bull. Amer. Meteor. Soc., 92, 1285-1296, https://doi.org/10.1175/2011BAMS3174.1.

Harpaz, T., B. Ziv, H. Saaroni, and E. Beja, 2014: Extreme summer temperatures in the East Mediterranean-Dynamical analysis. Int. J. Climatol., 34, 849-862, https://doi.org/10.1002/joc.3727.

Hu, K., G. Huang, and R. Huang, 2011: The impact of tropical Indian Ocean variability on summer surface air temperature in China. J. Climate, 24, 5365-5377, https://doi.org/10.1175/ 2011JCLI4152.1.

_ - _ X. Qu, and R. Huang, 2012: The impact of Indian Ocean variability on high temperature extremes across the southern Yangtze River valley in late summer. Adv. Atmos. Sci., 29, 91-100, https://doi.org/10.1007/s00376-011-0209-2.
IPCC, 2012: Managing the Risks of Extreme Events and Disasters to Advance Climate Change Adaptation. C. B. Barros et al., Eds., Cambridge University Press, 582 pp.

- 2014: Climate Change 2014: Impacts, Adaptation, and Vulnerability. Part B: Regional Aspects. V. R. Barros et al., Eds., Cambridge University Press, 688 pp., http://www.ipcc.ch/pdf/ assessment-report/ar5/wg2/WGIIAR5-PartB_FINAL.pdf.

Kanamitsu, M., W. Ebisuzaki, J. Woollen, S.-K. Yang, J. J. Hnilo, M. Fiorino, and G. L. Potter, 2002: NCEP-DOE AMIP-II Reanalysis (R-2). Bull. Amer. Meteor. Soc., 83, 1631-1643, https://doi.org/10.1175/BAMS-83-11-1631.

Kilbourne, E. M., 1997: Heat waves and hot environments. The Public Health Consequences of Disasters, E. K. Noji, Ed., Oxford University Press, 245-269.

Kim, J., K. J. Song, K. J. Hong, and Y. S. Ro, 2017: Trend of outbreak of thermal illness patients based on temperature 20022013 in Korea. Climate, 5, 94, https://doi.org/10.3390/cli5040094.

Kovats, R. S., and S. Hajat, 2008: Heat stress and public health: A critical review. Annu. Rev. Public Health, 29, 41-55, https:// doi.org/10.1146/annurev.publhealth.29.020907.090843.

Kunkel, K. E., X.-Z. Liang, and J. Zhu, 2010: Regional climate model projections and uncertainties of U.S. summer heat waves. J. Climate, 23, 4447-4458, https://doi.org/10.1175/ 2010JCLI3349.1.

Lau, N.-C., and M. J. Nath, 2012: A model study of heat waves over North America: Meteorological aspects and projections for the twenty-first century. J. Climate, 25, 4761-4784, https:// doi.org/10.1175/JCLI-D-11-00575.1.

- , and - 2014: Model simulation and projection of European heat waves in present-day and future climates. J. Climate, 27, 3713-3730, https://doi.org/10.1175/JCLI-D-13-00284.1.

Lippmann, S. J., C. M. Fuhrmann, A. E. Waller, and D. B. Richardson, 2013: Ambient temperature and emergency department visits for heat-related illness in North Carolina, 2007-2008. Environ. Res., 124, 35-42, https://doi.org/10.1016/ j.envres.2013.03.009.

Loikith, P. C., and A. J. Broccoli, 2012: Characteristics of observed atmospheric circulation patterns associated with temperature extremes over North America. J. Climate, 25, 7266-7281, https://doi.org/10.1175/JCLI-D-11-00709.1.

Lorenz, R., E. B. Jaeger, and S. I. Seneviratne, 2010: Persistence of heat waves and its link to soil moisture memory. Geophys. Res. Lett., 37, L09703, https://doi.org/10.1029/2010GL042764.

Lu, R.-Y., and R.-D. Chen, 2016: A review of recent studies on extreme heat in China. Atmos. Oceanic Sci. Lett., 9, 114-121, https://doi.org/10.1080/16742834.2016.1133071.

Luber, G., and M. McGeehin, 2008: Climate change and extreme heat events. Amer. J. Prev. Med., 35, 429-435, https://doi.org/ 10.1016/j.amepre.2008.08.021.

Luo, M., and N.-C. Lau, 2017: Heat waves in southern China: Synoptic behavior, long-term change, and urbanization effects. J. Climate, 30, 703-720, https://doi.org/10.1175/ JCLI-D-16-0269.1.

Maheras, P., H. Flocas, K. Tolika, C. Anagnostopoulou, and M. Vafiadis, 2006: Circulation types and extreme temperature changes in Greece. Climate Res., 30, 161-174, https://doi.org/ 10.3354/cr030161.

Meehl, G. A., and C. Tebaldi, 2004: More intense, more frequent, and longer lasting heat waves in the 21st century. Science, $\mathbf{3 0 5}$, 994-997, https://doi.org/10.1126/science.1098704.

Munich Re, 2011: Topics Geo: Natural catastrophes 2010: Analyses, assessments, positions. Munich Re, 58 pp., https:// www.preventionweb.net/files/17345_munichere.pdf. 
Nangombe, S., S. Madyiwa, and J. Wang, 2018: Precursor conditions related to Zimbabwe's summer droughts. Theor. Appl. Climatol., 131, 413-431, https://doi.org/10.1007/s00704-016-1986-4.

Oleson, K., G. Anderson, B. Jones, S. McGinnis, and B. Sanderson, 2018: Avoided climate impacts of urban and rural heat and cold waves over the US using large climate model ensembles for RCP8.5 and RCP4.5. Climatic Change, 146, 377-392, https://doi.org/10.1007/s10584-015-1504-1.

Pal, J. S., and E. A. B. Eltahir, 2016: Future temperature in southwest Asia projected to exceed a threshold for human adaptability. Nat. Climate Change, 6, 197-200, https://doi.org/ 10.1038/nclimate2833.

Park, J. K., R. Y. Lu, C. F. Li, and E. B. Kim, 2012: Interannual variation of tropical night frequency in Beijing and associated large-scale circulation background. Adv. Atmos. Sci., 29, 295-306, https://doi.org/10.1007/s00376-011-1141-1.

Perkins, S. E, 2015: A review on the scientific understanding of heatwaves-Their measurement, driving mechanisms, and changes at the global scale. Atmos. Res., 164-165, 242-267, https://doi.org/10.1016/J.ATMOSRES.2015.05.014.

Robinson, P. J., 2001: On the definition of a heat wave. J. Appl. Meteor., 40, 762-775, https://doi.org/10.1175/1520-0450(2001) $040<0762$ :OTDOAH $>2.0 . \mathrm{CO} ; 2$.

Rodionov, S. N., 2004: A sequential algorithm for testing climate regime shifts. Geophys. Res. Lett., 31, L09204, https://doi.org/ 10.1029/2004GL019448.

- 2006: Use of prewhitening in climate regime shift detection. Geophys. Res. Lett., 33, L12707, https://doi.org/10.1029/ 2006GL025904.

Rohde, R., and Coauthors, 2013a: Berkeley Earth temperature averaging process. Geoinf. Geostat. Overview, 1 (2), https:// doi.org/10.4172/2327-4581.1000103.

— , and Coauthors, 2013b: A new estimate of the average Earth surface land temperature spanning 1753 to 2011. Geoinf. Geostat. Overview, 1 (1), https://doi.org/10.4172/2327-4581.1000101.

Russo, S., A. F. Marchese, J. Sillmann, and G. Immé, 2016: When will unusual heat waves become normal in a warming Africa? Environ. Res. Lett., 11, 054016, https://doi.org/ 10.1088/1748-9326/11/5/054016.

Sandor, R. P., and W. B. Howe, 1997: Heat illness. Phys. Sportsmed., 25, 35-40, https://doi.org/10.1080/00913847.1997.11440257.
Stefanon, M., F. D'Andrea, and P. Drobinski, 2012: Heatwave classification over Europe and the Mediterranean region. Environ. Res. Lett., 7, 014023, https://doi.org/10.1088/17489326/7/1/014023.

Wang, M., X. Yan, J. Liu, and X. Zhang, 2013: The contribution of urbanization to recent extreme heat events and a potential mitigation strategy in the Beijing-Tianjin-Hebei metropolitan area. Theor. Appl. Climatol., 114, 407-416, https://doi.org/ 10.1007/s00704-013-0852-x.

Wang, W., W. Zhou, X. Wang, S. K. Fong, and K. C. Leong, 2013: Summer high temperature extremes in Southeast China associated with the East Asian jet stream and circumglobal teleconnection. J. Geophys. Res. Atmos., 118, 8306-8319, https://doi.org/10.1002/JGRD.50633.

$\longrightarrow,-$, X. Li, X. Wang, and D. Wang, 2016: Synoptic-scale characteristics and atmospheric controls of summer heat waves in China. Climate Dyn., 46, 2923-2941, https://doi.org/ 10.1007/s00382-015-2741-8.

Weaver, S. J., A. Kumar, and M. Chen, 2014: Recent increases in extreme temperature occurrence over land. Geophys. Res. Lett., 41, 4669-4675, https://doi.org/10.1002/2014GL060300.

Wei, J., and J. H. Sun, 2007: The analysis of summer heat wave and sultry weather in North China (in Chinese). Climatic Environ. Res., 12, 453-463.

Wu, J., X. Gao, F. Giorgi, and D. Chen, 2017: Changes of effective temperature and cold/hot days in late decades over China based on a high resolution gridded observation dataset. Int. J. Climatol., 37, 788-800, https://doi.org/10.1002/joc.5038.

Yang, H. L., Y. L. Xu, S. C. Tao, J. Pan, K. Liu, and M. S. Wu, 2010: Vulnerability to heat waves and adaptation: A summary (in Chinese). Sci. Technol. Rev., 28, 98-102.

Zaitchik, B. F., A. K. Macalady, L. R. Bonneau, and R. B. Smith, 2006: Europe's 2003 heat wave: A satellite view of impacts and land-atmosphere feedbacks. Int. J. Climatol., 26, 743-769, https://doi.org/10.1002/joc.1280.

Zhang, X., and Y. Wang, 2002: Relationship between power consumption and meteorological conditions during the summer in Beijing City and its forecast. Meteor. Mon., 28, 17-21.

Ziv, B., H. Saaroni, and P. Alpert, 2004: The factors governing the summer regime of the eastern Mediterranean. Int. J. Climatol., 24, 1859-1871, https://doi.org/10.1002/JOC.1113. 